\title{
Inductive surface geometries: Beyond morphogens and stem cells
}

SADJ September 2019, Vol. 74 No. 8 p421 - p444

U Ripamonti', R Duarte ${ }^{2}$

\section{ABSTRACT}

The requirement of biomimetic matrices for bone tissue engineering is now to construct functionalized surfaces with bioactive nanotopographical geometric cues. Functionalized surfaces prime stem cells to set into motion gene expression, synthesis and embedding of gene products within the functionalized surfaces.

Embedded proteins initiate the spontaneous induction of bone formation without the exogenous application of the soluble osteogenic molecular signals of the transforming growth factor- $\beta$ (TGF- $\beta$ ) supergene family.

Concavities cut by osteoclastogenesis along the surfaces of calcium phosphate-based biomimetic matrices are the driving morphogenetic cues that initiate the induction of bone formation biomimetizing the remodelling cycle of the cortico-cancellous bone. Geometric recognition activates mechano-transducer(s) that generate cytoskeletal motors that deforms the nuclear geometry, ultimately regulating stem cell differentiation.

Osteoclastogenesis drives nano-patterned geometric topographies releasing $\mathrm{Ca}^{++}$that induce angiogenesis and cellular differentiation. Expressed and secreted bone morphogenetic proteins (BMPs) are embedded into the implanted substrata initiating the induction of bone formation as a secondary response.

Cell attachment to geometrically modified titania' surfaces is controlled by Rho-associated kinase (ROCK) and focal adhesion kinase (FAK) up regulating the transcription factor RUNX2 controlling osteoblasts differentiation and BMPs expression. Geometry is the unifying biological theme of "finding meaning in complexity", a theme that sets morphogenetic inductive cues via nanotopographical surface modifications.

\section{Author affiliations:}

1. Ugo Ripamonti: $M D, P h D$., Bone Research Unit; School of Clinical Medicine - Internal Medicine, Faculty of Health Sciences, University of the Witwatersrand, Johannesburg

ORCID Number: 0000-0002-6567-3594

2. Raquel Duarte: BSc, Hons., PhD, Bone Research Unit and Laboratories of Molecular and Cellular Biology; School of Clinical Medicine - Internal Medicine, Faculty of Health Sciences, University of the Witwatersrand, Johannesburg. ORCID Number: 0000-0003-2750-2062

Corresponding author: Ugo Ripamonti

Bone Research Unit, 7 York Road, 2193 Parktown, South Africa.

Tel: +27 (0)117172144

Email: ugo.ripamonti@wits.ac.za

Author contributions:

1. Ugo Ripamonti: Primary author $-80 \%$

2. R Duarte: Secondary author $-20 \%$

\section{INTRODUCTION AND DEFINITIONS:}

Osteoinduction and osteoinductive biomaterials

The creative concept of this re-defining review on functionalized and osteoinductive surfaces of biomaterials arose during the preparation of a dissertation which focused on biomimetic matrices that drive the induction of bone formation. ${ }^{1}$

The associated revision of several papers warranted a review of a multitude of digital images and histological sections which had been generated on the phenomenon of the spontaneous and intrinsic osteoinductive activity of certain calcium phosphate-based macroporous bio-mimetic matrices. ${ }^{2,3}$

This revision and re-evaluation has led to the desire to focus on those functionalized surfaces which provide inductive microenvironments, set by the geometric configuration of a variety of treated or untreated surfaces of biomimetic matrices.

Our extensive revision together with the re-evaluation of seminal contributions on the induction of tissue morphogenesis by geometrically modified surfaces, emphasized the Leading Edge Editorial in Cell "Pulling It All Together". ${ }^{4}$

The extraordinary research on molecular cellular pathways and "seemingly infinite biological networks" has suggested a novel theme in future molecular and cellular studies: "Finding Meaning in Complexity". ${ }^{4}$

Similarly, since the last Century, a plethora of manuscripts has reached the pages of several Journals, reporting on the power of surface topography controlling cellular differentiation and gene expression mechanisms. Hence, this review wishes to present the unifying biological theme of geometry in leading the science of surfaces to construct biomimetic matrices that per se, in their own right, initiate the spontaneous induction of bone formation.

Geometry is indeed the unifying theme of "Finding Meaning in Complexity", a theme that brings together geometric cues that functionalize biomimetic surfaces. ${ }^{4}$

This review cannot proceed without unfolding the extraordinary uniqueness of the induction of bone formation so lucidly presented by MR Urist in Science as "Bone: formation by autoinduction" ${ }^{5}$ and by $\mathrm{AH}$ Reddi in the Proceedings National Academy of Science as "Biochemical sequences in the transformation of normal 
fibroblasts in adolescent rats" ${ }^{6}$ Both contributions describe the powerful "osteogenic activity" inherent within allogeneic, demineralized bone matrices, raising the fact that morphogens, defined by Turing as "forms generating substances" ${ }^{\prime}$, must exist within the implanted matrices.

In addition, their work proposes the development of morphogenetic gradients as being ultimately responsible for the induction of bone formation. ${ }^{7-12}$ Developmentally, morphogens are released from a localized group of embryonic cells or "organizing centers"11-13which induce cellular differentiation and morphogenesis. ${ }^{10}$

Research in the last century has shown that morphogens are at the very crux of tissue induction and morphogenesis in preclinical and clinical contexts. ${ }^{14-18}$

Whether morphogens' gradients self-organize specific morphogenetic patterns according to different diffusion properties or gradients ${ }^{7}$ or "influence each other in triggering the spontaneous emergence of stable, long-range patterns of morphogen activity"19, only "Morpheus unbound" 19 can initiate the cascade of pattern formation and the induction of tissue morphogenesis. ${ }^{19,20}$

This review wishes to re-discover critical references on the role of geometry on tissue transformation and on the induction of bone formation. ${ }^{21-24}$ Such references and images set the theme of this communication that wishes to convey the proposal that it is surface geometry, at the macroscopic and microscopic, nano-topographic, levels, that establishes the molecular and cellular parameters for the differentiation of various microenvironments that initiate the ripple-like cascade of tissue induction and morphogenesis. ${ }^{25-27}$

The induction of tissue morphogenesis, and in this context, the induction of bone formation, is thus not the sole prerogative of the soluble osteogenic molecular signals. It is the result of a connubium of the supramolecular assembly of the soluble molecular signals together with the insoluble signal or substratum that ultimately controls and modulates the powerful inductive activity of the morphogenetic soluble signals. ${ }^{20-23,28-30}$

\section{Osteoinductive biomaterials}

How can we define an "osteoinductive biomaterial"? The term induction, firstly used by Spemann, ${ }^{13}$ was later re-deployed by Levander, Moss, Urist and Reddi. ${ }^{17}$

The latter also introduced the term "transformability" and "transformation" of "normal fibroblasts in adolescent rats". ${ }^{6}$ These transformative events may be set into motion by morphogenetic gradients available to responding cells after implantation of acid/alcohol extracted biological matrices including diaphyseal bone matrices. ${ }^{16-18,27}$

A classic paper that highlighted the emerging concept of "bioactivity" was published by Hulbert et al. ${ }^{31}$, recognizing the critical role of porosity in biomaterials' design and incorporation. ${ }^{31}$
This contribution showed that macroporous hydroxyapatites constructed with an interconnecting porous network allowed for osteo-conduction and that macroporous hydroxyapatites with pores sizes greater than $150 \mu \mathrm{m}$ were seen to host the formation of osteonic remodeling bone. ${ }^{31}$

The paper further highlighted that bone growth into the ceramic structure "was analogous to the infiltration of a cancellous bone structure by new compact Haversian bone", thus suggesting biomimetism of the invading trabecular bone structure within the implanted calcium phosphate-based matrix. ${ }^{31}$

An inductive biomaterial is thus a biomaterial that together with (or in combination with) soluble osteogenic molecular signals initiates the ripple-like cascade of tissue induction and bone morphogenesis. ${ }^{16-18}$

The acid test in defining an osteoinductive biomaterial is to demonstrate its osteoinductivity in heterotopic extra skeletal sites, either intramuscularly ${ }^{5}$ or subcutaneously. ${ }^{6}$ This avoids the ambiguities of the orthotopic site, where bone formation occurs from the viable bone at the interfaces of treated defects. ${ }^{5,6,16-18}$

The classic work of Levander, Moss, Huggins, Urist, and Reddi ${ }^{27,29,30}$ culminated in the biological understanding that intact bone and dentin demineralized matrices are endowed with the striking prerogative of the de novo initiating endochondral bone formation when implanted in heterotopic intramuscular or subcutaneous sites of rodents and lagomorphs $s^{5,6,16-18,27-30}$

The question now arises whether a biomaterial without the exogenous application of osteogenic soluble molecular signals can, in its own right, initiate the cascade of bone differentiation by induction, even when implanted in heterotopic extra skeletal sites where there is no bone? Reporting verbatim the introductory statements of a seminal contribution to Nature ${ }^{32}$, Gustav Levander asks whether tissue regeneration "develops merely from pre-existing cells, which grow out from the original cell-units, or may also some other material be imagined as participating in the occurrence of regeneration?"

Levander further states that "it has simply been taken for granted that when bone formation is obtained, this must have emanated from transferred bone cells". ${ }^{32}$ Using non-vital alcohol extracts of bone tissue implanted intramuscularly in animal models, Levander reported that newly formed bone initiated by induction "within the fully developed organism under the influence of an extractable substance". ${ }^{32}$

Levander concludes that "the circumstance that a tissue is able to affect another in a specifically differentiating direction I have termed induction, a term borrowed by Spemann and his school at the turn of the Century". ${ }^{13,32}$

Such "an extractable substance" marks the beginning of the understanding of morphogenetic substances or morphogens that set the stage of tissue induction and morphogenesis..$^{5-7,14-18}$ The concluding statements 
of the Levander communication in Nature are wrought to a powerful biological platform that seals the tissue-engineering paradigm by stating, "regeneration of tissue is, in other words, a repetition of embryonal development". ${ }^{32}$

The same "extractable substance" is active both during the embryonal differentiation and during postfetal growth. ${ }^{32}$ On this great truth is deeply rooted the dream of the tissue engineering paradigm: morphogens exploited in embryonic development can be re-deployed to mechanistically initiate post-natal tissue induction. ${ }^{14-18,27,30}$

Bone and dentine, as applies to all mineralized matrices, are in the solid state, yet have compartmentalized soluble signals interacting with responding cells. In an incisive mini review in Cell, ${ }^{33}$ Reddi states that bone "is in both a soluble and a solid state that is regulated by signals in solutions interacting with the extracellular matrix", and that "a beautiful example of the interface of signals and extracellular matrix is the human skeleton" 33 and further that the "skeleton is a giant molecular machine" [AH Reddi, personal communication 2014].

Identification of putative morphogens within the bone matrix was further complicated by the fact that small quantities of proteins are bound to both the organic and inorganic components of the extracellular matrix of bone. ${ }^{16-18,34}$ Solubilization of putative osteogenic soluble molecular signals was classically achieved by the chaotropic extraction of the intact demineralized extracellular matrix of bone (A chaotropic agent is a molecule in water solution that can disrupt hydrogen bondings)..$^{16-18,35,36}$

The chaotropic extraction did result in the isolation of soluble molecular signals and an insoluble signal, or substratum, the insoluble collagenous bone matrix (ICBM) obtained after the dissociative extraction of the extra cellular matrix of bone. ${ }^{16-18,34,35}$

The chaotropic dissociative extraction of $4 \mathrm{M}$ guanidinium hydrochloride $(\mathrm{Gdn}-\mathrm{HCl})$ or $6 \mathrm{M}$ Urea unlocked the problem of the "bone matrix in the solid state". ${ }^{33}$ The solubilized proteins indicated that the extracellular matrix of bone is a large repository of morphogenetic signals. ${ }^{14-18}$

Solubilized signals or proteins were thus purified to homogeneity by newly designed chromatographic procedures and cloned. ${ }^{15-18 ; 37-39}$ The expression of the recombinant human morphogenetic proteins (BMPs) showed homology with several other inductive and differentiating morphogens of the transforming growth factor- $\beta$ (TGF- $\beta$ ) supergene family. ${ }^{15-18 ; 37-39}$

The grand experimentation of Reddi's group defined the operational reconstitution of the purified soluble osteogenetic molecular signals with an insoluble signal or substratum, ${ }^{33-37}$ acting as a carrier to deliver the biological activity of the purified osteogenic proteins.

The inactive and insoluble collagenous bone matrix after chaotropic dissociative extraction when "recon- stituted"35 with the solubilized osteogenic molecular signals, restored the bone induction cascade, ${ }^{35}$ propelling the "bone induction principle" 40 in clinical contexts. ${ }^{16-18}$

The systematic experimentation of Reddi and coworkers on the "bone induction principle" 40 established the critical role of the carrier substratum as a delivery system for the biological activity of the extracted proteins. ${ }^{14-18,36,37}$

Since the early nineties, we have reported a novel and exciting concept of tissue engineering and regenerative medicine: the induction of bone formation upon the implantation of intrinsically osteoinductive biomaterials.
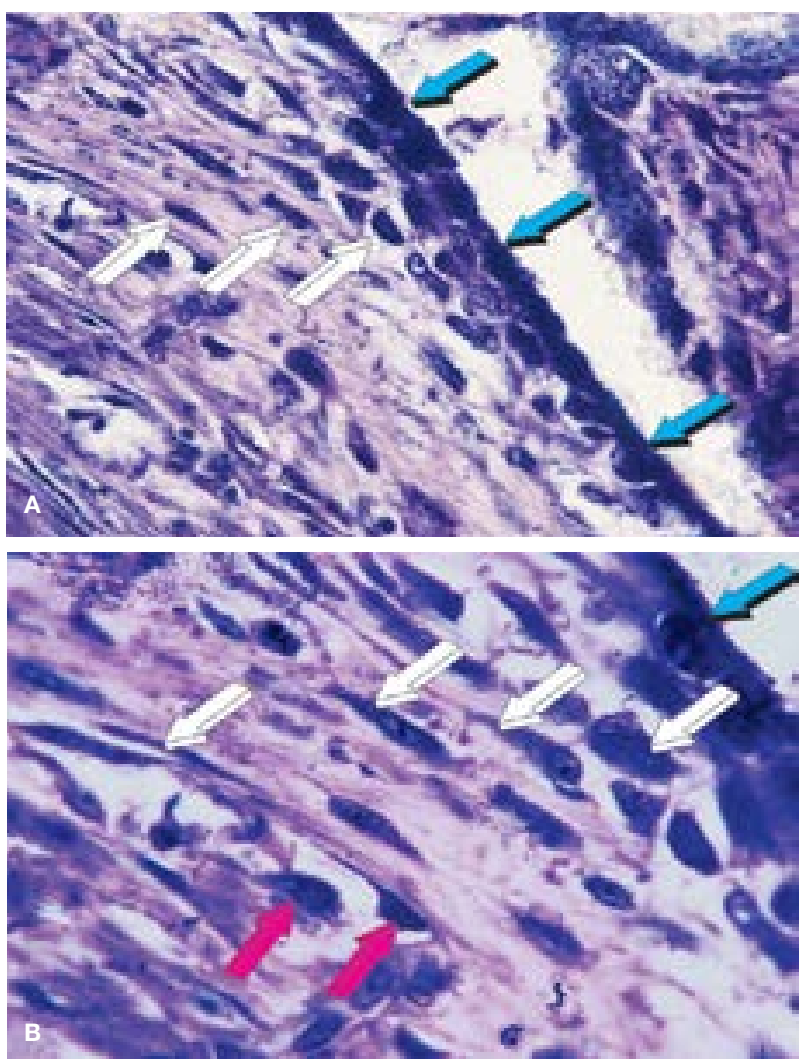

Figure 1. Coral-derived constructs ${ }^{2,3,41}$ were implanted in the rectus abdominis muscle of adult male Chacma baboons Papio ursinus and generated tissues harvested on day 30,60 and 90 for morphological and histomorphometrical analyses including alkaline phosphatase staining and immunolocalization studies for laminin, type I and IV collagens. Undecalcified specimen blocks were embedded in Historesin (LKB Bromma Sweden) as described. ${ }^{41}$

A. Undecalcified section cut on day 60: differentiation of cellular elements within the invaded macroporous spaces at the hydroxyapatite interface directly onto the hydroxyapatite substratum (light blue arrows). Differentiating cells, interpreted as osteoblasts, are directly differentiating against the hydroxyapatite surface. Differentiating cells are continuously provided by migrating osteoprogenitors from the vascular compartment (white arrows). B. Nucleation and differentiation of osteoblasts at the hydroxyapatite interface (light blue arrow). The differentiating or "transformation microenvironment" at the hydroxyapatite interface is continuously fed by responding migrating osteoprogenitors cells (white arrows) that migrate from the vascular compartment towards the osteogenic compartment of the transformation microenvironment.

Note the different status of cellular differentiation as seen morphologically according to the relative migration across morphogenetic gradients established by the transforming microenvironments at the substratum' interface. Large cells with hypertrophic nuclei (magenta arrows) differentiate attached to the basement membranes of the invading capillaries providing thus, as per Trueta' definition ${ }^{54}$, osteogenetic vessels for the constant supply of responding cells migrating from the vascular to the osteogenic compartment of the transformation microenvironment. Undecalcified sections cut at $6 \mu \mathrm{m}$ (Polycut-S, Reichert, Heidelberg, Germany) stained free-floating with toluidine blue in $30 \%$ ethanol.

Original magnification: $(A) \times 125$; (B) $\times 175$. 

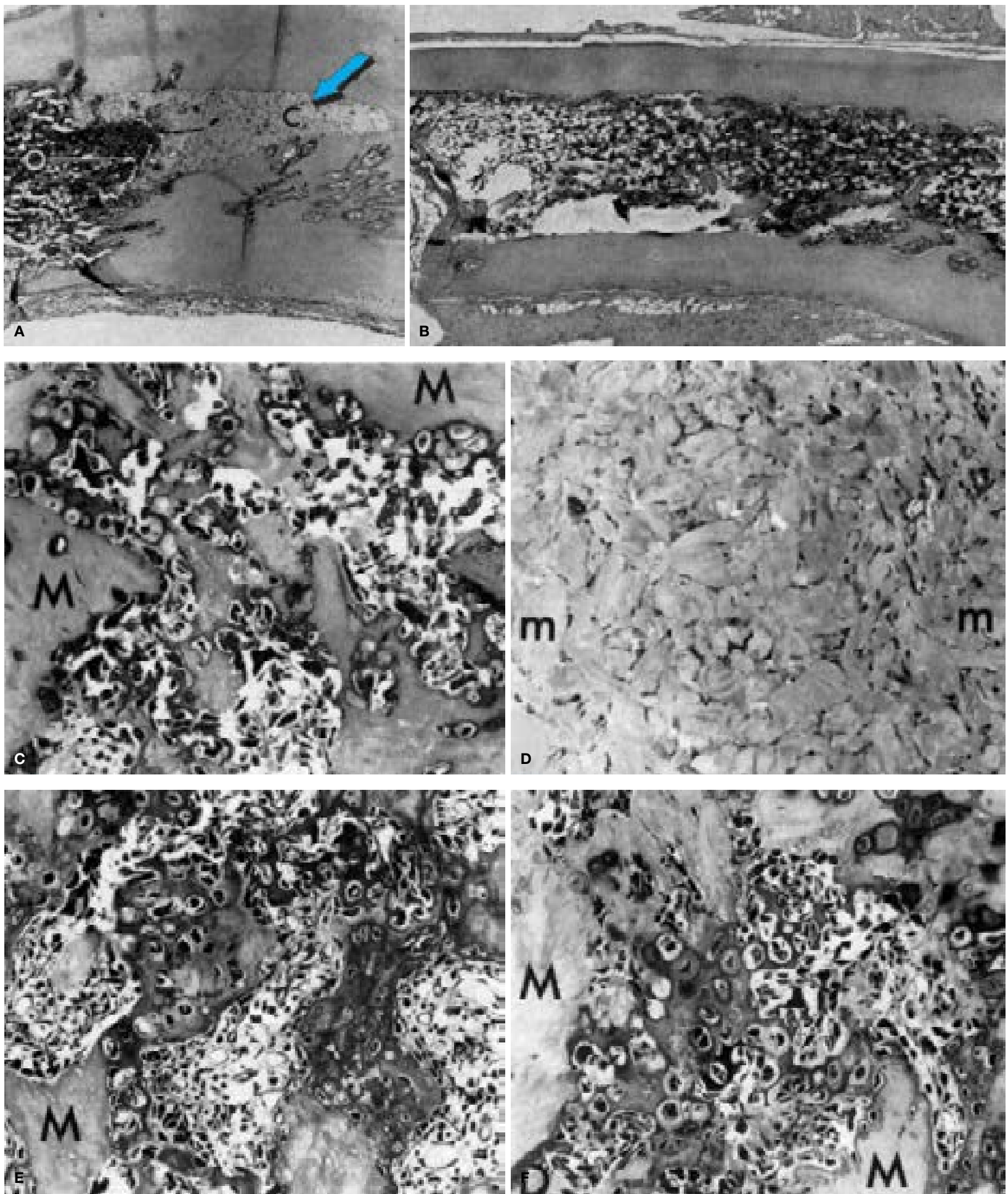

Figure 2. Tissue induction and morphogenesis by geometrically different inductive substrata: the effect of substratum geometry on the induction of endochondral bone formation. Courtesy of AH Reddi, Influence of Geometry of Transplanted Tooth and Bone on Transformation of Fibroblasts. Proceedings of the Society for Experimental Biology and Medicine: 143: $634-7,1973,{ }^{21}$

A. Demineralized whole incisor harvested on day 28 after heterotopic implantation in the subcutaneous space of recipient rodents. ${ }^{21}$ Bone formation by induction with the development of an ossicle $(\mathrm{O})$ with bone marrow. The root apex is populated by newly formed cartilage (C) (light blue arrow). B. Open demineralized tooth incisor (after apex resection) shows the induction of bone with marrow formation across the pulp chamber but lack of cartilage formation. As reported, ${ }^{21}$ the "temporal sequence of fibroblast-chondroblast-osteoblast transformation was profoundly influenced by the geometry of the transformant." Undecalcified sections, original magnification (A) $\times 2.7$; (B) $\times 1.7$. C.D.E.F. The effect of geometry of demineralized bone matrix (DBM), the inductor, on tissue induction and differentiation upon implantation in the subcutaneous space of the rat. ${ }^{23}$

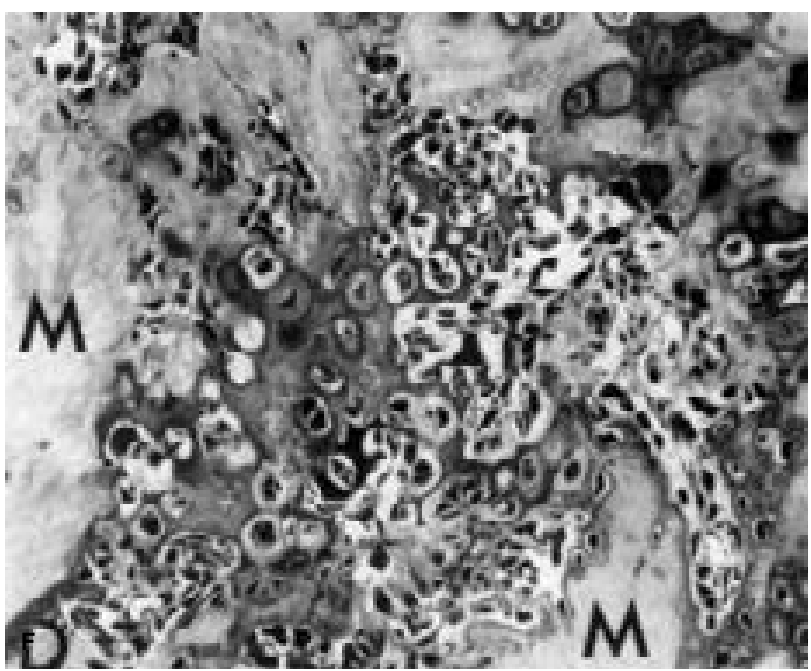

Courtesy of AH Reddi "The Journal of Cell Biology", Importance of geometry of the extracellular matrix in endochondral bone differentiation. 98: 2192-7, $1984 .^{23}$

C. Heterotopic induction of bone formation by coarse demineralized matrix (M) (light blue arrows) particle size 74-420 $\mu \mathrm{m}$ : vascular invasion, chondrolysis and induction of bone formation.

D. Fine matrix (m) (light blue arrows): complete lack of bone differentiation. E. Reconstitution of coarse collagenous inactive residue matrix $(\mathrm{M})$ with fine matrix $\mathrm{Gdn} \mathrm{HCl}$ extracts: restoration of the bone induction activity with vascular invasion.

F. Reconstitution of coarse matrix (M) (light blue arrows) with fine matrix $\mathrm{Gdn}-\mathrm{HCl}$ extracts further purified by gel filtration chromatography on Sepharose CL-CB, equilibrated in $4 \mathrm{M}$ Gdn HCl/50 mM Tris, $\mathrm{pH}$ 7.0:23 Complete restoration of the bone induction cascade with prominent vascular invasion induced by purified proteins from fine matrix. ${ }^{23}$ Fine matrix thus contains osteogenic proteins, but the geometry of the inductor blocks the bone induction cascade. Undecalcified sections, original magnification (C,D) x125; (E,F) ×200. 
These are materials that per se, in their own right, retain the prerogative of inducing desired and specific morphogenetic responses when implanted in heterotopic extra skeletal sites, where there is no bone, and without the exogenous application of the soluble osteogenic molecular signals of the TGF- $\beta$ supergene family. $2,3,34,41,42$

Before discussing and highlighting the mechanistic insights of the "geometric induction of bone formation" 43,44 we re-present microphotographs we generated after experimentation in the non-human primate Papio ursinus (Fig. 1). ${ }^{41}$ The study involved heterotopic intramuscular implantation of coral-derived macroporous bioreactors in the rectus abdominis muscle. ${ }^{41}$

Serial undecalcified sections were prepared from specimen blocks harvested on days 30,60 and 90. Sections showed large plumped hyperchromatic cells interpreted as differentiating osteoblasts directly apposed to the hydroxyapatite surface (Fig. 1). The presented images summarize more than twenty-seven years of systematic research on osteoinductive biomaterials, and lucidly highlight the direct effect of the substratum upon cell differentiation and the induction of the osteogenic phenotype. ${ }^{41}$

\section{The geometric induction of bone formation}

In the late eighties we were exposed to the unique finding that coral-derived calcium phosphate-based macroporous bioreactors induced the morphogenesis of bone when implanted in the rectus abdominis muscle of the Chacma baboon Papio ursinus. ${ }^{2,3}$ Of great significance was the observation that the heterotopic induction of bone formation was initiated without the exogenous application of the soluble osteogenic molecular signals of the TGF- $\beta$ supergene family. ${ }^{45}$

The realization that the insoluble signal, ie. the substratum alone, could initiate the induction of bone formation, modified the tissue engineering paradigm: soluble signals, when recombined with insoluble signals or substrata, initiate the cascade of bone formation by induction. ${ }^{14-18}$ The serendipitous discovery of osteoinductive biomaterials per $s e^{2,3}$ paved the way to the design of novel substrata to explore the effect of surface topography on cell shape and differentiation. Topographical geometric surface' modifications regulate the molecular machinery controlling the expression of selected mRNA species of the osteogenic phenotype, resulting in tissue induction and morphogenesis. ${ }^{46}$

The influence of geometry on tissue induction and bone formation has been demonstrated by the classic papers of Reddi's group that highlighted the critical role of geometry of the substratum on the induction of bone formation (Fig. 2). ${ }^{21-24} \mathrm{~A}$ new set of experiments were thus designed using coral-derived calcium phosphate constructs pre-loaded with doses of highly purified naturally derived osteogenic fractions, purified greater than 50,000 - fold $^{23}$ for implantation in the subcutaneous space of Long-Evans rats. ${ }^{28}$

The constructs were of two geometric configurations, i.e. blocks in disc form $(7 \mathrm{~mm}$ in diameter, $3 \mathrm{~mm}$ in height) and granules (400-620 $\mu \mathrm{m}$ in diameter) of porous hydroxyapatite replicas. ${ }^{28}$

Reconstituted specimens with or without osteogenic proteins $(50 \mu \mathrm{g}$ osteogenic proteins fraction per implant) were bioassayed in the subcutaneous space of LongEvans rats at bilateral sites over the pectoralis fascia and harvested on days 7, 11 and 21 after implantation ${ }^{28}$ (Fig. 3).

Strikingly, the induction of bone formation was observed only in - the hydroxyapatite discs treated with osteogenic proteins (Fig. 3). Induction of bone formation failed to occur in implants of particulate/granular hydroxyapatite even when the particulates had been pre-treated with highly purified osteogenic fractions. Bone did not form in any of the coral-derived configurations without osteogenic proteins. ${ }^{28}$

New experiments were later initiated using the rectus abdominis muscle of Papio ursinus to exploit the hydroxyapatite-induced osteogenesis model to test the osteoinductive potential of macroporous constructs with different geometric configurations, and without the exogenous applications of the osteogenic molecular signals of the TGF- $\beta$ supergene family. ${ }^{47}$

Coral-derived bioreactors in block/cylinder configurations were implanted in the rectus abdominis muscle and tested against granular particulate coral-derived constructs implanted contra laterally. ${ }^{47}$ Specimens harvested on days 60 and 90 provided histological material that unequivocally showed the influence of the geometry of the substrate on the induction of bone formation (Fig. 4). ${ }^{47-53}$ Coral-derived constructs in block/ cylinder configuration did induce the spontaneous and intrinsic induction of bone formation within the macroporous spaces. ${ }^{47}$ Particulate/granular coral-derived constructs in general failed to initiate the induction of bone formation (Fig. 4).

One particulate/granular coral-derived specimen showed the induction of bone formation within a concavity of the implanted hydroxyapatite substratum (Figs. 4B,C). The reported images were instrumental in the identification of the concavity as an initiator of the bone induction cascade in macroporous coral-derived bioreactors when implanted in heterotopic sites of Papio ursinus (Fig. 4). ${ }^{47-53}$ The observation also suggested the revision of all available histological records of macroporous bioreactors previously implanted in the rectus abdominis of Papio ursinus (Figs. 5,6).

The induction of bone formation by coral-derived and sintered macroporous hydroxyapatites-based bioreactors: the concavity, the shape of life

Histological re-evaluation and re-analyses was completed on old as well as newly cut and stained sections from coral-derived hydroxyapatite specimen blocks, and including newly prepared undecalcified sections.

The assessments lead to the formulation of the hypothesis that the induction of bone formation by coralderived calcium phosphate-based macroporous bio- 

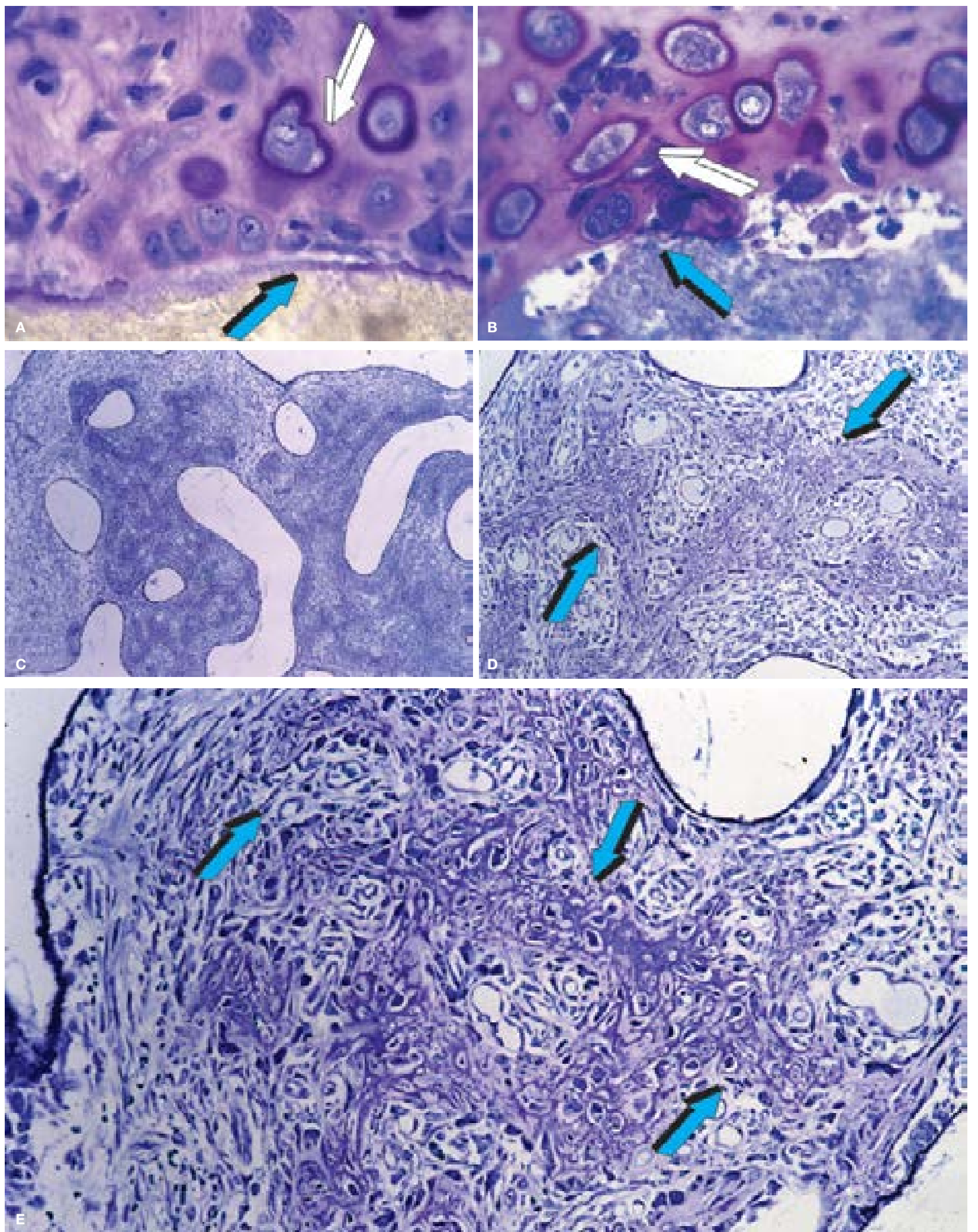

Figure 3. Tissue induction and morphogenesis by geometrically different coral-derived hydroxyapatite constructs pre-loaded with highly purified bovine osteogenic fractions implanted in the subcutaneous apace of Long-Evans rats. Tissue specimens, harvested on day 7,11 and 21 after heterotopic implantation, were subjected to undecalcified histological analyses and alkaline phosphatase assay ${ }^{28}$

$(A, B)$ Differentiation of large chondroblastic cells (white arrows) with cartilaginous matrix secreted at the hydroxyapatite interface on day 7 after heterotopic implantation (light blue arrows). ${ }^{28}$

$(C, D, E)$ Other specimens, also on day 7 , show the direct induction of intramembranous bone formation regulated by the angiogenetic and morphogenetic vessels of Trueta' and Aristotle' definition. ${ }^{18,30,54}$ Trabeculae of newly formed bone populated by contiguous osteoblasts

(light blue arrows) form around the morphogenetic vessels ${ }^{18,27,30}$ that construct the primordial osteonic structure of long-lived vertebrate's' bones. The remarkable and florid induction of bone formation as shown in $(\mathrm{C}, \mathrm{D}, \mathrm{E})$ markedly contrast with the lack of bone differentiation (not shown). Additional experiments were conducted to exclude that the specific activity of osteogenic proteins bound to the substrata could be affected by the geometric configurations of the coral-derived substrata ${ }^{28}$. The binding and/or release of recombinant human bone morphogenetic protein was not affected by the geometry of the coral-derived substrata since rhBMP-2 $\mathrm{b}^{28}$ binds equally well to coral-derived constructs in granular and disc configurations. ${ }^{28}$ Undecalcified sections stained with toluidine blue. ${ }^{28}$

Original magnification: (A,B) x200; (C) x75; (D) x175; (E) x200; (F) x 175 


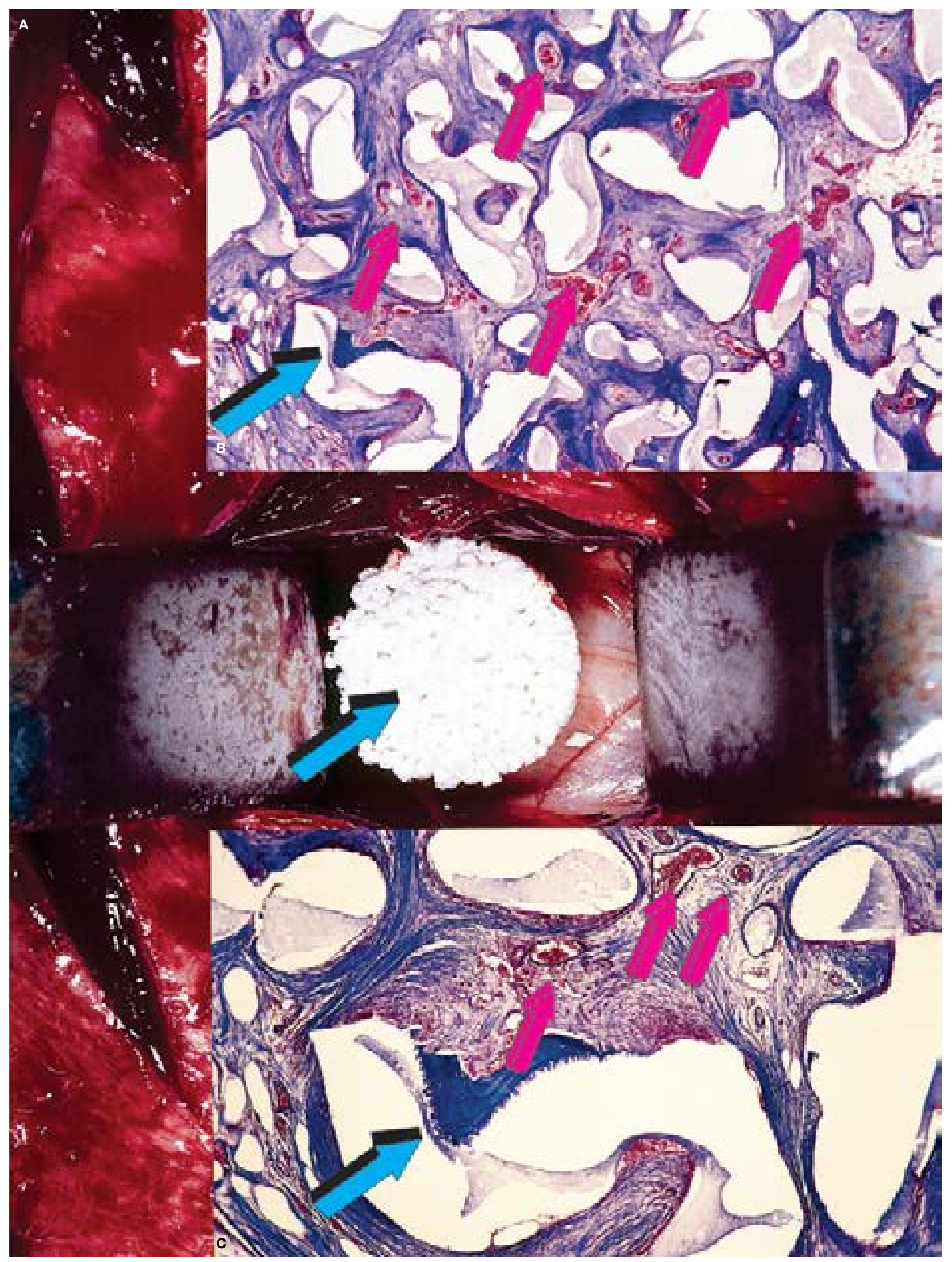

Figure 4. The effect of substratum' geometry on the induction of bone formation by coral-derived macroporous constructs implanted in the rectus abdominis muscle of adult Papio ursinus and harvested on day 60 and 90 after heterotopic implantation. ${ }^{47}$ Coral-derived constructs were rods $20 \mathrm{~mm}$ in height and $7 \mathrm{~mm}$ in diameter, and particulate/granular construct pelleted for heterotopic implantation (A) (light blue arrow) in intramuscular pouches created by sharp and blunt dissection of the rectus abdominis muscle ${ }^{47}$.

B. Histological analyses of particulate/granular coral-derived constructs show the lack of bone differentiation across the specimen. One section only (ight blue arrow) showed the minimal yet positive induction of bone formation in a concavity of the particulate/granular coral-derived construct (C) (light blue arrow). This particular section and digital image sparkled the interest on the geometric induction of bone formation and called for a mandatory revision of several previously cut specimens which again highlighted the critical role of the substratum geometry on the induction of bone formation without the exogenous applications of soluble osteogenic proteins of the transforming growth factor- $\beta$ (TGF- $\beta$ ) supergene family.45 Decalcified sections cut at $6 \mu \mathrm{m}$, original magnification (B) x75; (C) x175. 

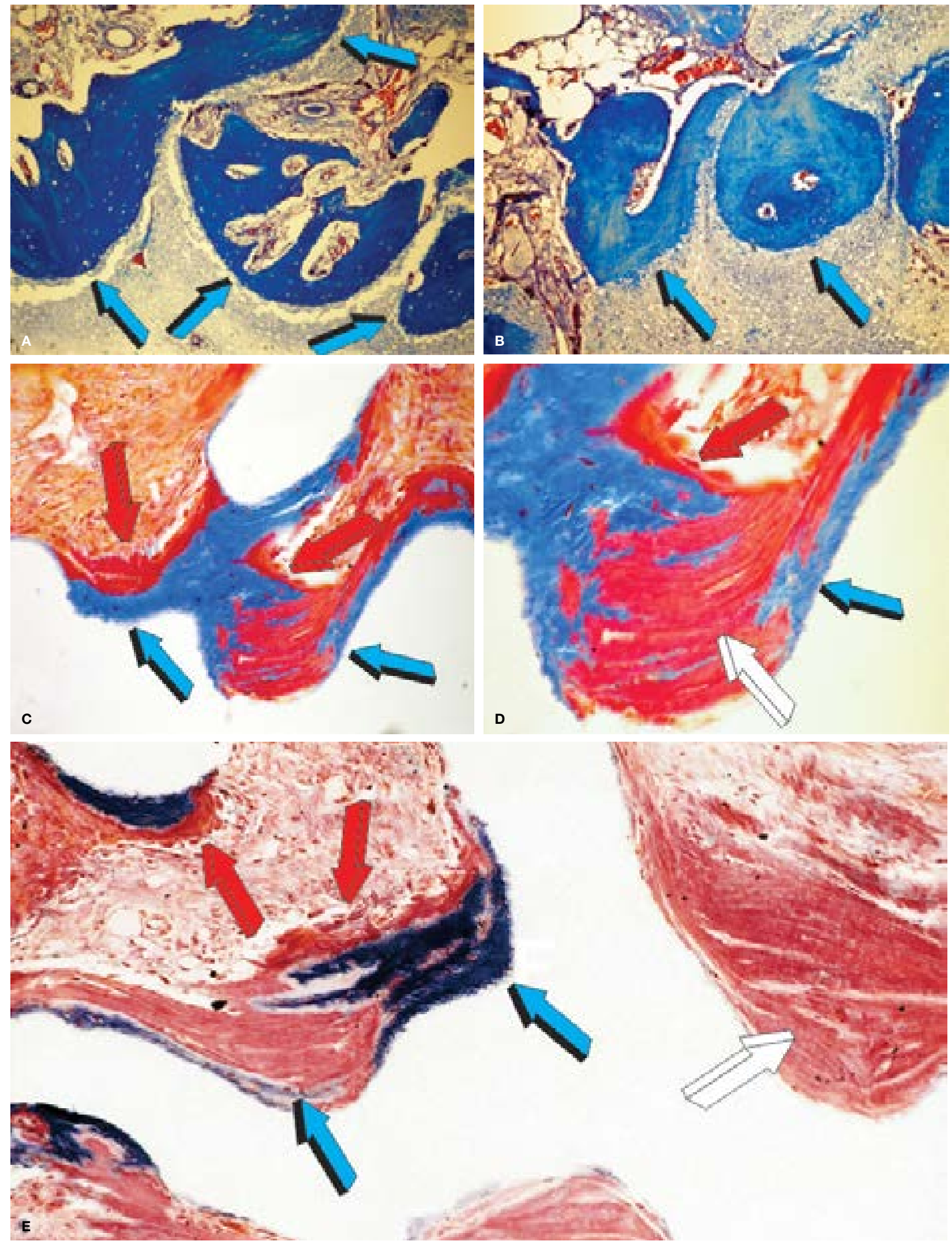

Figure 5. The "intrinsic" induction of bone formation regulated by the geometry of the substratum. Macroporous rods of coral-derived bioreactors were implanted in the rectus abdominis muscle of Papio ursinus and harvested on day 90 after implantation. $2.3,20,29,47-50$ Revision of several specimens harvested from the rectus abdominis muscle of Papio ursinus in the late eighties and early nineties were re-examined and often recut to expand on the biological meaning of the images presented in Figs. 4B,C. These invocated the concavity as a critical geometric signal to initiate the induction of bone formation in macroporous coral-derived constructs. A,B. (light blue arrows) Induction of substantial bone formation within concavities of the macroporous bioreactors.

C,D,E. Undecalcified sections illustrating the induction of mesenchymal condensations at the hydroxyapatite interface (white arrows) predating mineralization (light blue arrows) of the collagenous condensations with the differentiation of osteoblastic-like cells secreting newly formed osteoid matrix (red arrows) onto the mineralized condensations. Bone initiates within the concavities of the implanted substratum without the exogenous application of the osteogenic proteins of the TGF- $\beta$ supergene family $47-50$ Decalcified sections cut at $6 \mu \mathrm{m}$, original magnification $(A, B) \times 45 ;(C, D, E)$. Undecalcified sections cut at $6 \mu \mathrm{m}$ stained free-floating with Goldner's trichrome, original magnification (C) $\times 75$; (D) $\times 125$; (E) $\times 80$. 


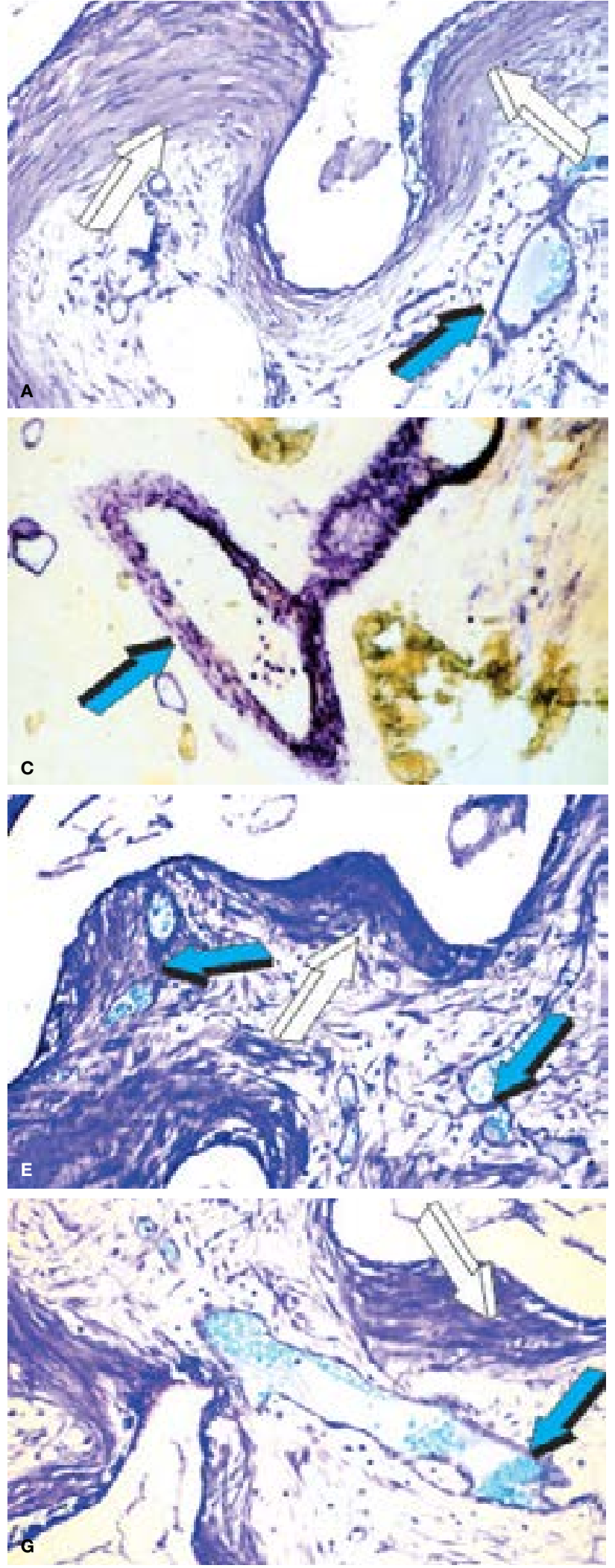

Figure 6. Induction of collagenous condensations and angiogenesis with differentiation of osteogenetic vessels on days 30 and 60 after heterotopic intramuscular implantation of coral-derived bioreactors harvested on days 30 and 60 . A,B. Concavities of the substratum are invaded by fibro vascular tissue that organize as mesenchymal collagenous condensations within the invaded macroporous spaces (white arrows). Invasion of the macroporous spaces by capillary sprouting in close relationship with the substratum (light blue arrows). Angiogenetic vessels show intense alkaline phosphates activity $(C, D)$ elongating to almost touch the implanted bioreactor (light blue arrows) (E). F. Invading capillaries immunolocalize laminin within the basement membranes (white arrow). Angiogenic and osteogenic proteins bind to type IV collagen of the capillaries' base-
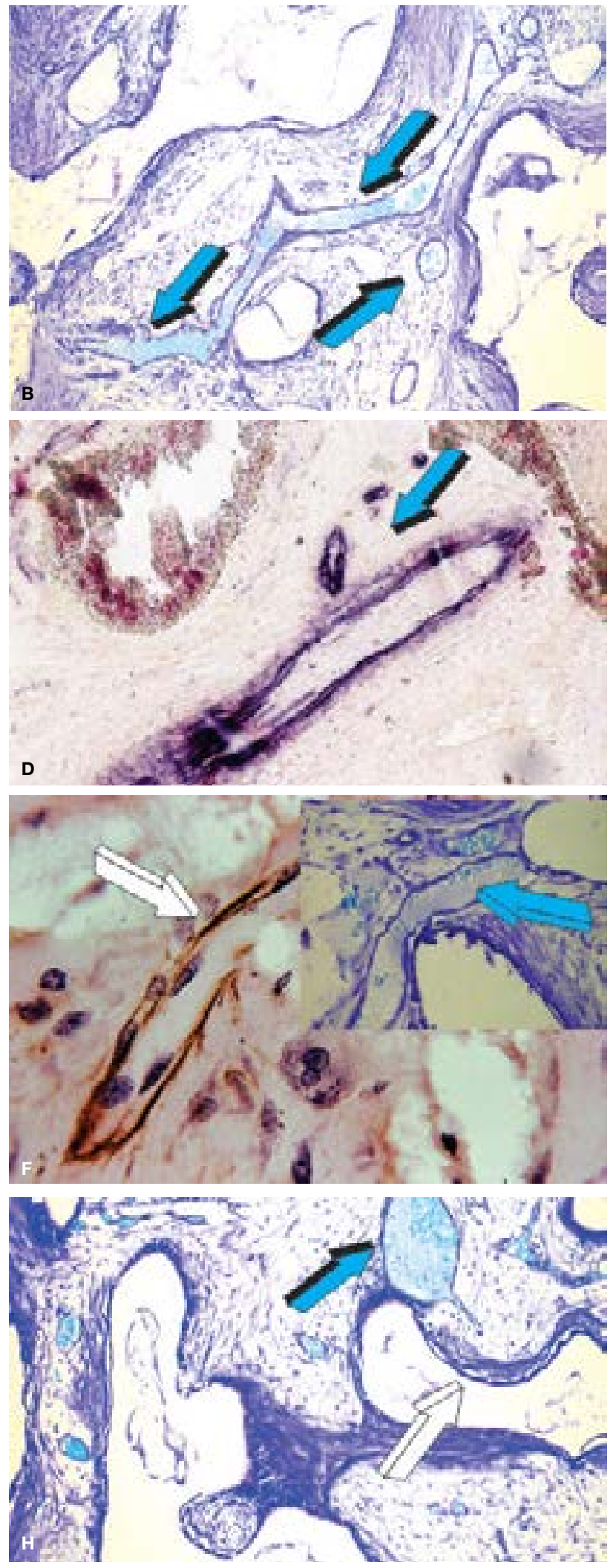

ment membrane. ${ }^{16,18}$ Type IV collagen may thus function as a storage and delivery system by sequestering both angiogenic and osteogenic proteins. ${ }^{16,18} \mathrm{G}, \mathrm{H}$. Continuous remodelling of collagenous condensations (white arrow) within the concavities of the macroporous spaces of coral derived constructs on day 60 after heterotopic implantation. Note the prominent vascular invasion and capillary sprouting (light blue arrow) within the macroporous spaces tightly connected with the differentiating and remodelling mesenchymal condensations. Decalcified and undecalcified sections $(C, D, E)$ cut at $6 \mu \mathrm{m}$, original magnification $(A, B) \times 65 ;(C, D)$ Undecalcified sections cut at $6 \mu \mathrm{m}$ stained free-floating with Goldner's trichrome, original magnification $(\mathrm{C}, \mathrm{D}, \mathrm{F}) \times 75 ;(\mathrm{G}, \mathrm{H}) \times 60$. 

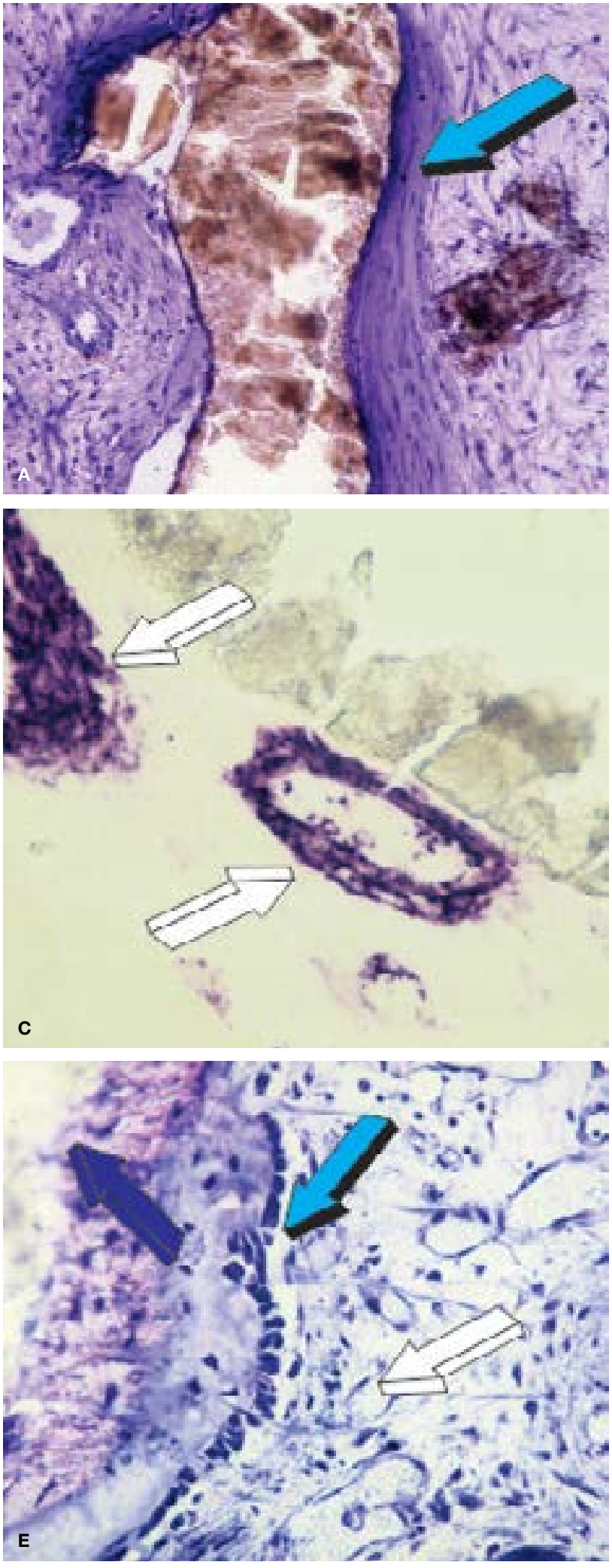

Figure 7. Collagenous condensations, morphogenesis of the "osteogenetic vessels" of Trueta' definition ${ }^{54}$ and the induction of bone formation tightly bound to the coral-derived hydroxyapatite surface on day 30 and 60 after heterotopic rectus abdominis implantation. ${ }^{41}$

A. Collagenous condensations align directly against the hydroxyapatite substratum on day 30 (light blue arrow).

B. Serial section specular image of (A) showing prominent alkaline phosphatase staining of invading capillaries (white arrows B) but lack of alkaline phosphatase staining of the collagenous condensations, day 30 (light blue arrow A). C. Capillaries attached to the hydroxyapatite substratum show multilayers of alkaline phosphatase positive cells in the wall of the invading and embracing vessels on day 30 (white arrows).

D. Induction of collagenous condensations on day 60 depicting promi-
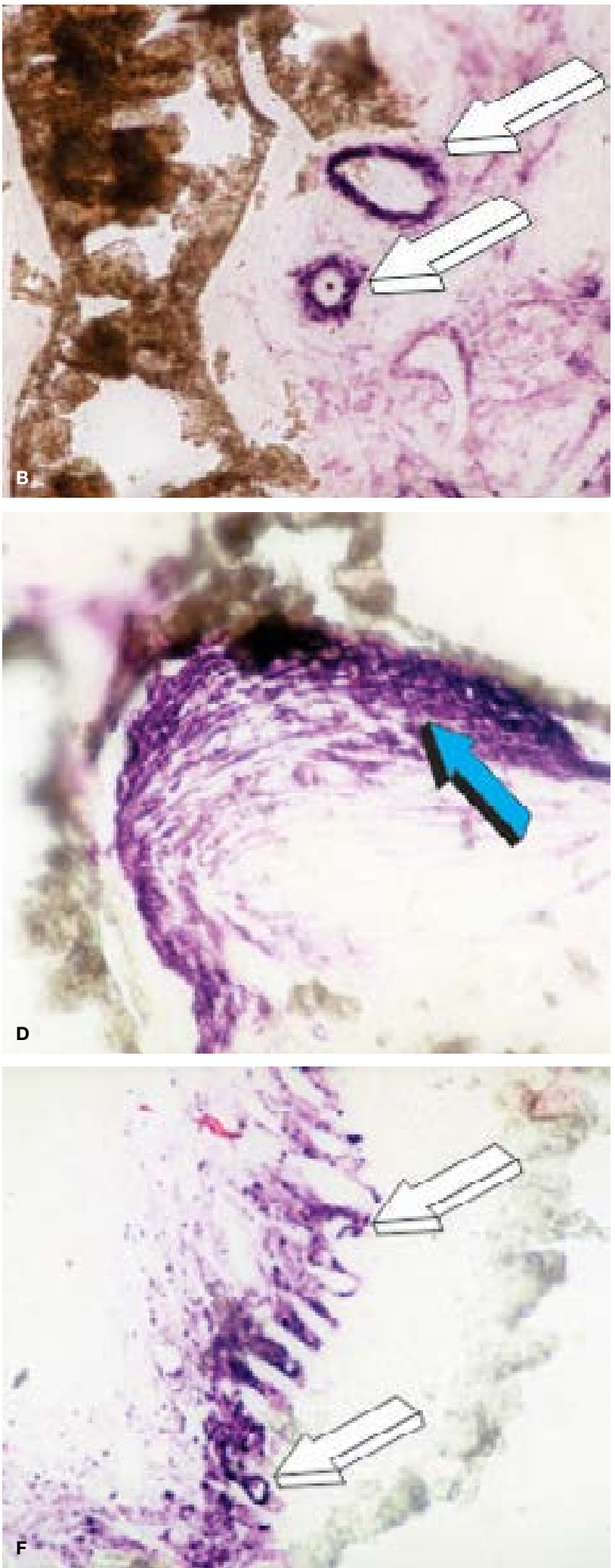

nent alkaline phosphatase staining of the condensations particularly at the transformation microenvironment (light blue arrow) as illustrated in Fig. 1. E,F. The induction of bone formation on day 60. Newly deposited osteoid matrix is surfaced by contiguous plumped osteoblastic-like cells secreting osteoid (light blue arrow). E. The mineralized newly formed matrix is tightly attached to the hydroxyapatite substratum (dark blue arrow), so the osteoid matrix that is anchored to the mineralized bone by penetrating fibres. Several capillaries (white arrow) are invading the contiguous space of the newly formed bone. F. Adjacent section $20 \mu \mathrm{m}$ apart from image depicted in (E), day 60 , showing alkaline phosphatase staining of secreting contiguous osteoblasts. Undecalcified sections cut at $6 \mu \mathrm{m}$ stained with toluidine blue in $30 \%$ ethanol; original magnification $(A, B) \times 100$; (C) $\times 210$; (D) $\times 125 ;(E, F) \times 175$ 
reactors is initiated within the concavities of the substratum. We then conceived that the concavity is a powerful morphological, cellular and molecular inductive signal for the induction of bone formation ${ }^{43-53}$ (Figs. 5,6).

A time study was henceforth implemented using coralderived constructs, harvested on days 30, 60 and 90 , in the endeavour to identify some of the mechanisms of the intrinsic and/or spontaneous induction of bone formation..$^{41}$ Decalcified and undecalcified sections were subjected to histomorphometrical and immuno histochemical analyses, the latter characterizing the developing collagenous condensations (Fig. 7D), the vascular invasion (Figs. 6C,D; 7B,C), the further remodelling of the collagenous condensations (Fig. 6E), and the induction of bone formation (Figs. 7E,F). Sprouting capillaries within the macroporous spaces showed strong alkaline phosphatase staining on several layers of the cells on the walls of the vessels (Figs. 6C,D;7C). These stained capillaries represent the classic "osteogenetic vessels" as defined by Trueta. ${ }^{54}$

Osteogenetic vessels invaded the macroporous spaces and were in intimate association with the macroporous constructs, providing osteogenetic precursor cells which would attach to the substratum for further differentiation into the osteoblastic-phenotype ${ }^{41}$ (Figs. 6C,D;7B,C).

The basement membrane of invading capillaries showed immunolocalization of laminin, an extracellular matrix basement component (Fig. 6F). Laminin displays amino acid motifs that directly control the phenotypic differentiation and modulation of osteoblastic-like cells in vitro. ${ }^{18,33}$

By day 60, collagenous condensation (Fig. 6A) of immunolocalized type I collagen was seen, with alkaline phosphatase staining ${ }^{41}$ (Fig. 7D). Staining of invading capillaries which were directly facing the hydroxyapatite substratum was prominent on day 30 (Figs. 6C,D; 7B,C) with later induction of bone formation (Figs. 7E,F).

The newly formed bone faced a highly vascular invading mesenchymal tissue by day 60 , with alkaline phosphatase positive cells secreting bone matrix (Figs. 7E,F). Immunolocalization of the extracellular matrix of the invading capillaries included laminin and type IV collagen (Fig. 6F).

Almost thirty years ago, the question that arose was how to correlate the geometric signal of the concavity with the spontaneous induction of bone formation? The concavity as cut in macroporous calcium phosphate-based macroporous constructs is similar to the concavities generated by osteoclastogenesis during the remodelling cycle of the cortico-cancellous osteonic bone ${ }^{55,56}$ (Fig. 8). There is thus a profound biomimetism of the "geometric induction of bone formation" $43,44,50$ with the remodelling cycle of the cortico-cancellous osteonic bone ${ }^{55,56}$ (Figs. 8C,D).

The critical role of the concavity initiating and controlling the induction of bone formation in primates was later established using crystalline sintered hydroxy-apatite substrata both as macroporous bioreactors (Figs. $9,10)$ and as crystalline highly sintered hydroxy-apatite discs prepared with a series of concavities on both planar surfaces (Fig. 11A).

Constructs were implanted heterotopically in the rectus abdominis muscle of Papio ursinus. ${ }^{48,49,51}$ A substantial amount of bone was formed by day 90 within the concavities of both coral-derived (Figs. 9A,B) and highly crystalline hydroxyapatite substrata (Figs. 9C,D).

The induction of bone formation was comparable between substrata with occasionally substantial induction of bone by sintered macroporous constructs (Fig. 9D). Classically, the induction of bone formation was seen on day 30 in the concavities of macroporous sintered bio-reactors (Fig. 10).

Histological sections cut across highly sintered crystalline discs showed the initiation of bone formation only within the concavities as early as day 30 post implantation (Figs. 11B,C).

Immunohistochemical studies showed intracellular cytoplasmic immunostaining of OP-1, also known as BMP-7, within resting differentiating mesenchymal cells at the hydroxyapatite interface (Fig. 11D). Sections taken at 30 days also showed the immuno-localization of OP-1, secreted and embedded onto the hydroxyapatite substratum (Fig. 11E).

Sections cut on day 90 after implantation showed the critical role of the concavity microenvironment in controlling the induction of bone formation with bone remodelling and the induction of hematopoietic marrow (Fig. 11F).

Geometrically modified crystalline hydroxyapatitecoated titanium implants do initiate the spontaneous induction of bone formation in heterotopic intramuscular sites

The induction of bone formation by macroporous sintered constructs produced with a series of repetitive concavities (Figs. 12A,B) was repeated with solid titanium cylinders configured with a series of concavities across the titanium surface which was coated with highly sinter-

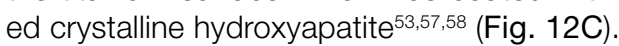

The implant body has an outer surface which defines a plurality of concavities, each having a maximum diameter of about $1600 \mu \mathrm{m}$, and a maximum depth of about $800 \mu \mathrm{m}$. Concavities are spaced apart a distance of about $800 \mu \mathrm{m}^{53,57}$ (Fig. 12C). A Metco 9MB plasma spray gun operating with an $\mathrm{Ar} / \mathrm{H} 2$ plasma at $35 \mathrm{~kW}$ was used to deposit a coating thickness of about 60 to $80 \mu \mathrm{m}$ of hydroxyapatite powder (Metco-Plasma Technick product AMDRY 6020).

The hydroxyapatite was of high crystallinity and low porosity, resulting in a film highly adherent to the titanium surfaces. ${ }^{53,57}$ Prior to spraying the titanium substrata had been roughened by grit blasting with alumina grit to produce the following surface profiles: $\mathrm{Ra}>3 \mu \mathrm{m}, \mathrm{R} 1>20 \mu \mathrm{m}, \mathrm{R}->15 \mu \mathrm{m}$ (Figs. 14A,B). ${ }^{53,57}$ 
The hydroxyapatite coated titanium implants were inserted orthotopically in edentulous mandibular ridges and along the exposed ventral tibiae in a number of adult Papio ursinus ${ }^{53,57}$ (Fig. 12C) (Animal Research Ethics Committee - AREC - applications: 2010/36/04; 2011/28/05).

Hydroxyapatite-coated titanium geometric constructs were also implanted in the rectus abdominis muscle to test the osteoinductive activity of the concavity microenvironment as sculpted in titanium constructs coated with crystalline hydroxyapatite.

Harvested specimens implanted in the rectus abdominis muscle on day 5 after intramuscular implantation ${ }^{53,57}$ were prepared for SEM analyses and provided critical insights into the early cellular events initiating within the concavities of the hydroxyapatite-coated titanium substrata (Fig. 13).

Plasma hydroxyapatite-coated constructs without geometric configurations showed limited, if any, cellular attachment along the exposed planar sintered hydroxyapatite coating ${ }^{53,57,58}$ (Figs. 13 C,D).

In marked contrast, titanium constructs coated with crystalline highly sintered hydroxyapatite with concavities across the planar surface showed the prominent induction of cell proliferation and alignment within the exposed concavities to the rectus abdominis intramuscular micro-environment (Figs. 13E,F;14A).

Mesenchymal cellular elements secreted collagenic material around the edges of the concavities (Fig. 14A), bridging the concavities which were exposed to the rectus abdominis intramuscular microenvironment.

Cellular bridging with the establishment of cellular tractional forces resulted in the deposition of collagenous material across the concavities (Fig. 14A), indicating that secreting fibroblast-like cells were moving back and forward along the secreted collagen fibres, continuously laying down collagen across the edges of the concavities.

This was later mineralized as bundle bone across the margins of the concavities on the highly sintered crystalline hydroxyapatite discs (Figs. 14B,C).

Figure 8. Anatomical, functional and molecular biomimetic correlation of the induction of bone formation within concavities cut by osteoclastogenesis in the primate cortico-cancellous trabecular bone vs. the concavities as assembled in macroporous highly sintered hydroxyapatite constructs. The remodelling cycle of the cortico-cancellous bone is characterized by the resorption phase as initiated by osteoclastogenesis. ${ }^{55,56}$

$A, C$. At any given time and area of the trabecular bone microarchitecture, osteoclastogenesis sculpts specific geometries in the form of concavities excavated within the trabecular bone (light blue arrows in A,C). The geometry in the form of a concavity is a specific cue imprinted during the remodelling phases of the cortico-cancellous bone of primates. ${ }^{18,55,56}$ Osteoclastogenesis sets the release of $\mathrm{Ca}^{++}$and other factors including bone morphogenetic proteins from the resorbed matrix. The deposition phase then follows with angiogenesis and osteoblast recruitment which, when attached to the resorbed lacunae of the bone matrix, synthetize osteoid matrix (B,C magenta arrows). The intrinsic and/or spontaneous induction of bone formation ( $\mathrm{D}$ dark blue arrow) is initiated by a local
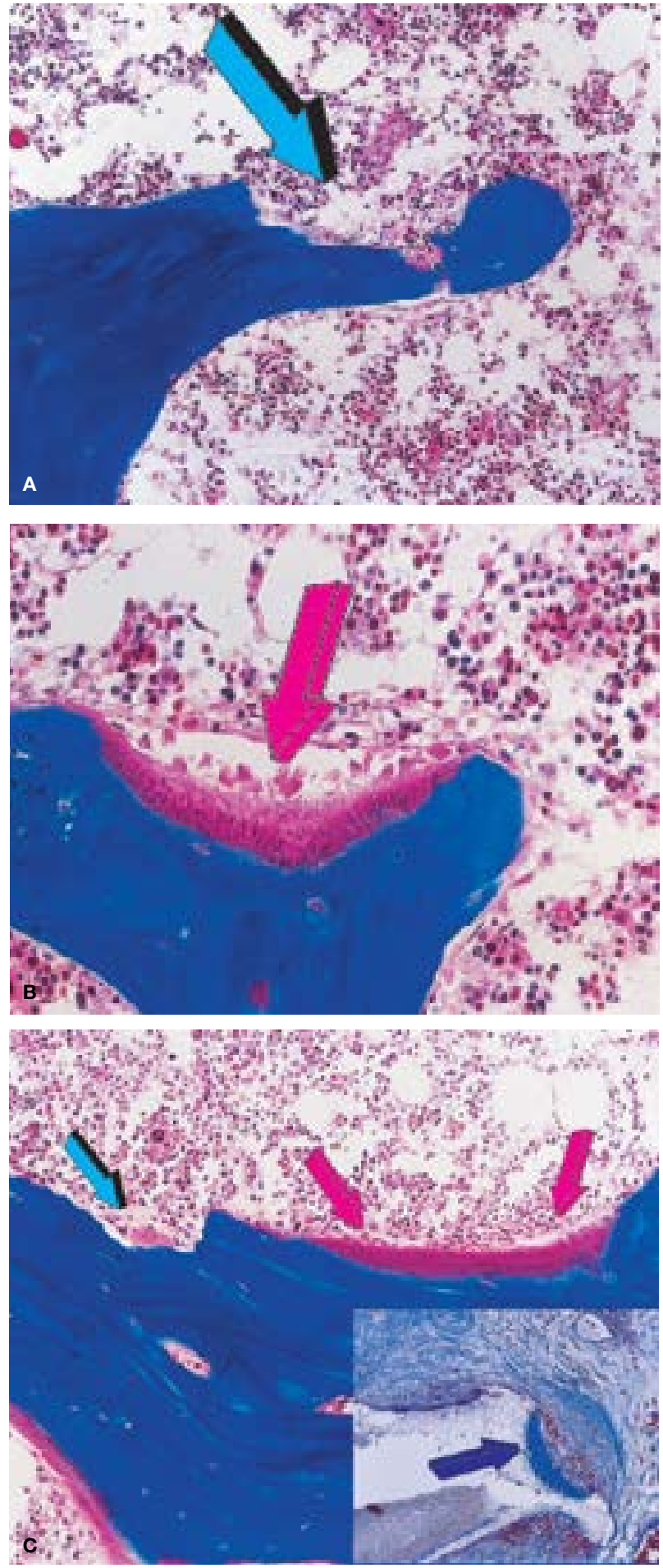

peak of $\mathrm{Ca}^{++}$activating stem cell differentiation and the induction of bone formation. ${ }^{46}$ Osteoclastogenesis is a critical event controlling the initiation of bone formation by coral-derived macroporous constructs, and it is required to set nano-patterned geometric topographies, which, together with $\mathrm{Ca}^{++}$release, induce angiogenesis, cell differentiation, osteoblasts cell matrix deposition with bone morphogenetic proteins expression and synthesis. ${ }^{63}$ Expression of BMPs follows the embedding of the secreted gene products into the implanted matrices with the induction of bone formation as a secondary response. ${ }^{46}$ Preloading coralderived constructs with the osteoclast inhibitor zoledronate zometa or the calcium channel blocker verapamil hydrochloride blocks and reduces significantly the induction of bone formation. ${ }^{46}$ Zoledronate-treated specimens showed a delay of the induction of mesenchymal collagenous condensations at the hydroxyapatite interface, with minimal BMP-2 expression on day 15. Notably, the loss of osteoclast binding resulted in up-regulation of Noggin on day 15, correlating to minimal induction of bone formation by 60 and 90 days after heterotopic rectus abdominis implantation. ${ }^{46}$ Undecalcified sections cut at $6 \mu \mathrm{m}$ stained free-floating with Goldner's trichrome, original magnification $(A, B, C, D) \times 175$. 

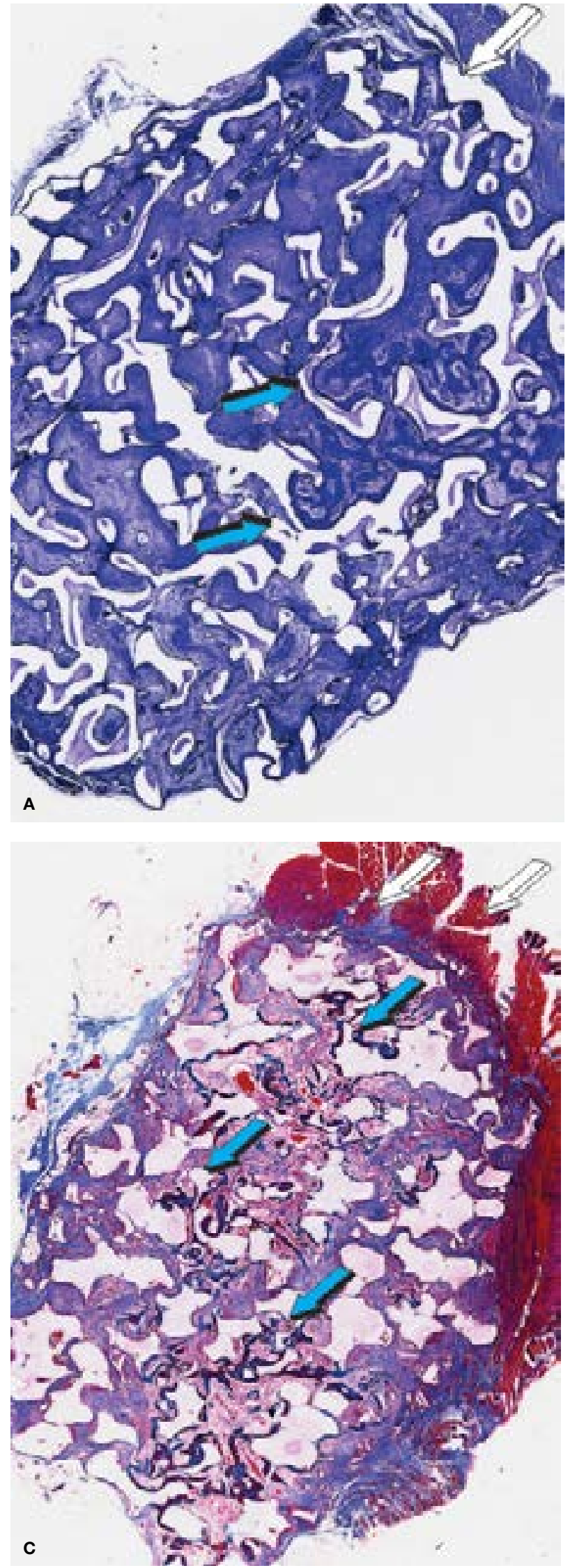

Figure 9. Tissue induction and morphogenesis by calcium-phosphatebased macroporous constructs 90 days after heterotopic implantation in the rectus abdominis muscle (white arrows) of the non-human primate Papio ursinus.

A,B. Low power views of coral-derived bioreactors. Bone formation by induction (light blue arrows) across the macroporous spaces. Collagenous
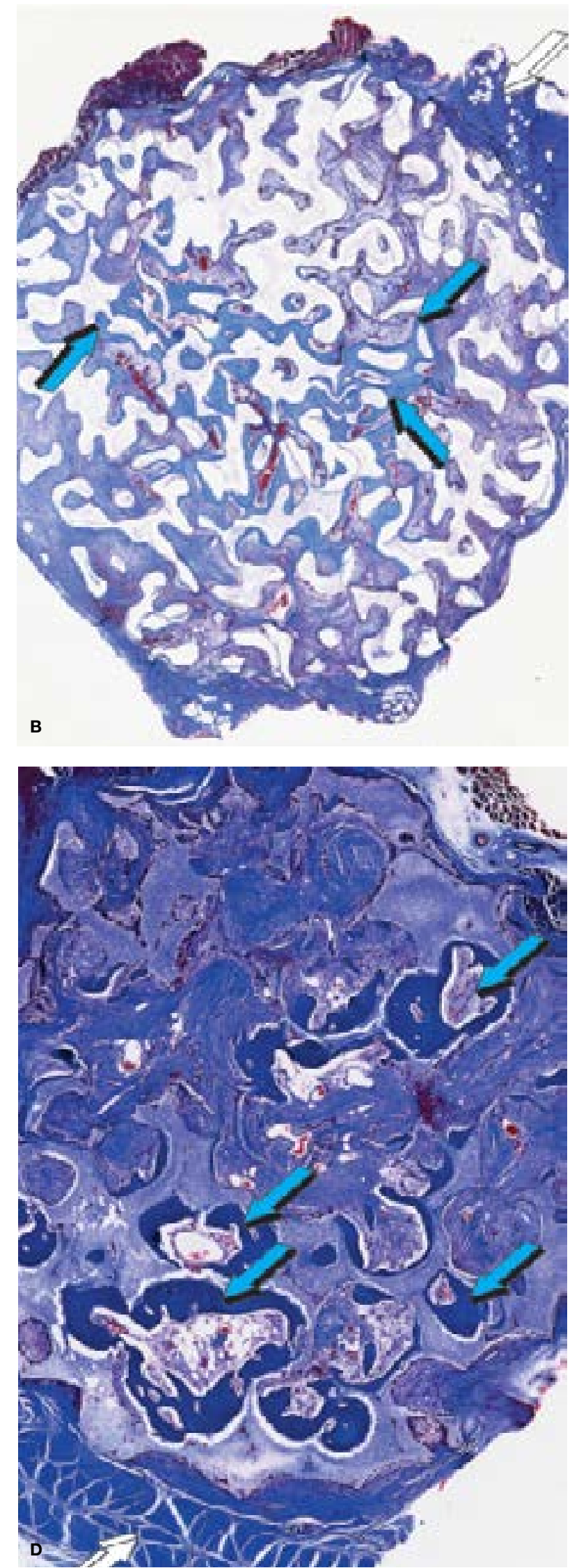

condensations form across the specimens tightly attached and aligned along the surfaces.

C,D. Induction of bone formation across the macroporous spaces (light blue arrows) by sintered crystalline macroporous constructs. Decalcified sections cut at $6 \mu \mathrm{m}$ stained with toluidine blue in $30 \%$ ethanol $(A)$ and with Goldner's trichrome $(B, C, D)$; original magnification $(A, B, C, D) \times 7.5$ 

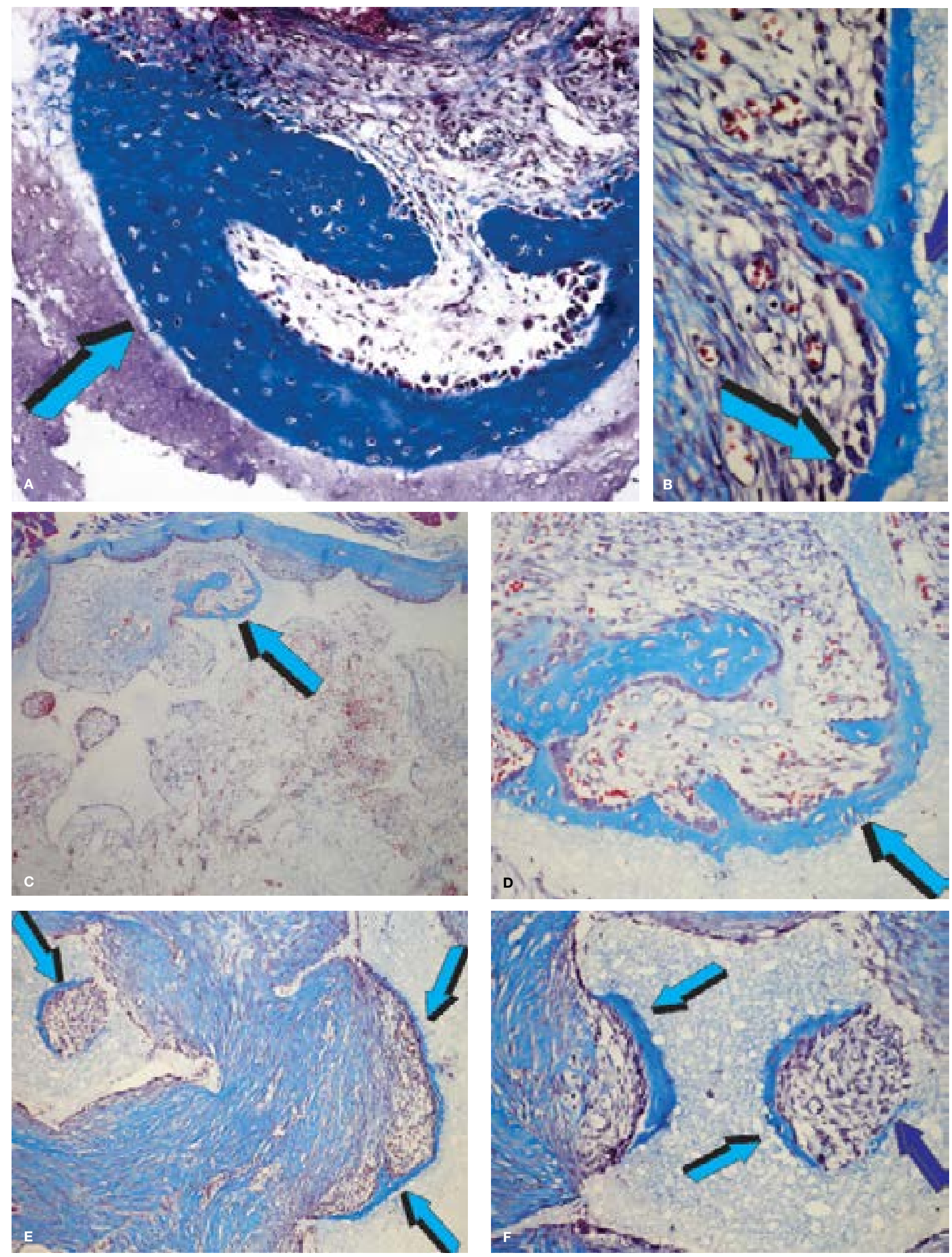

Figure 10. The geometric induction of bone formation by repetitive sequences of concavities (light blue arrows) assembled in macroporous constructs of highly sintered crystalline hydroxyapatite biomatrices after heterotopic implantation in the rectus abdominis muscle of the non-human primate Papio ursinus.

A. Bone formation within a concavity of the substratum surfaced by contiguous osteoblasts facing a highly vascularized matrix on day 90 . B. The newly formed bone by day 30 is tightly attached to the substratum (light blue arrow) with contiguous plumped osteoblasts (light blue arrow).

C,D. Induction of bone formation within the concavity of the highly crystalline bioreactor showing cellularity of the newly formed bone (C,D light blue arrows) tightly attached to the crystalline substratum (D).

E,F. Precision induction of bone formation exclusively in concavities of the highly crystalline biomatrix (light blue arrows) on day 30 after heterotopic implantation. Bone forms intrinsically within concavities of the bioreactor (light blue arrows) 30 days after implantation in the rectus abdominis muscle. Decalcified sections cut at $6 \mu \mathrm{m}$ stained with toluidine blue in $30 \%$ ethanol. Original magnification (A) x35; (B) x90; (C) x17; (D) x90; (E) $\times 27 ;(F) \times 31$. 

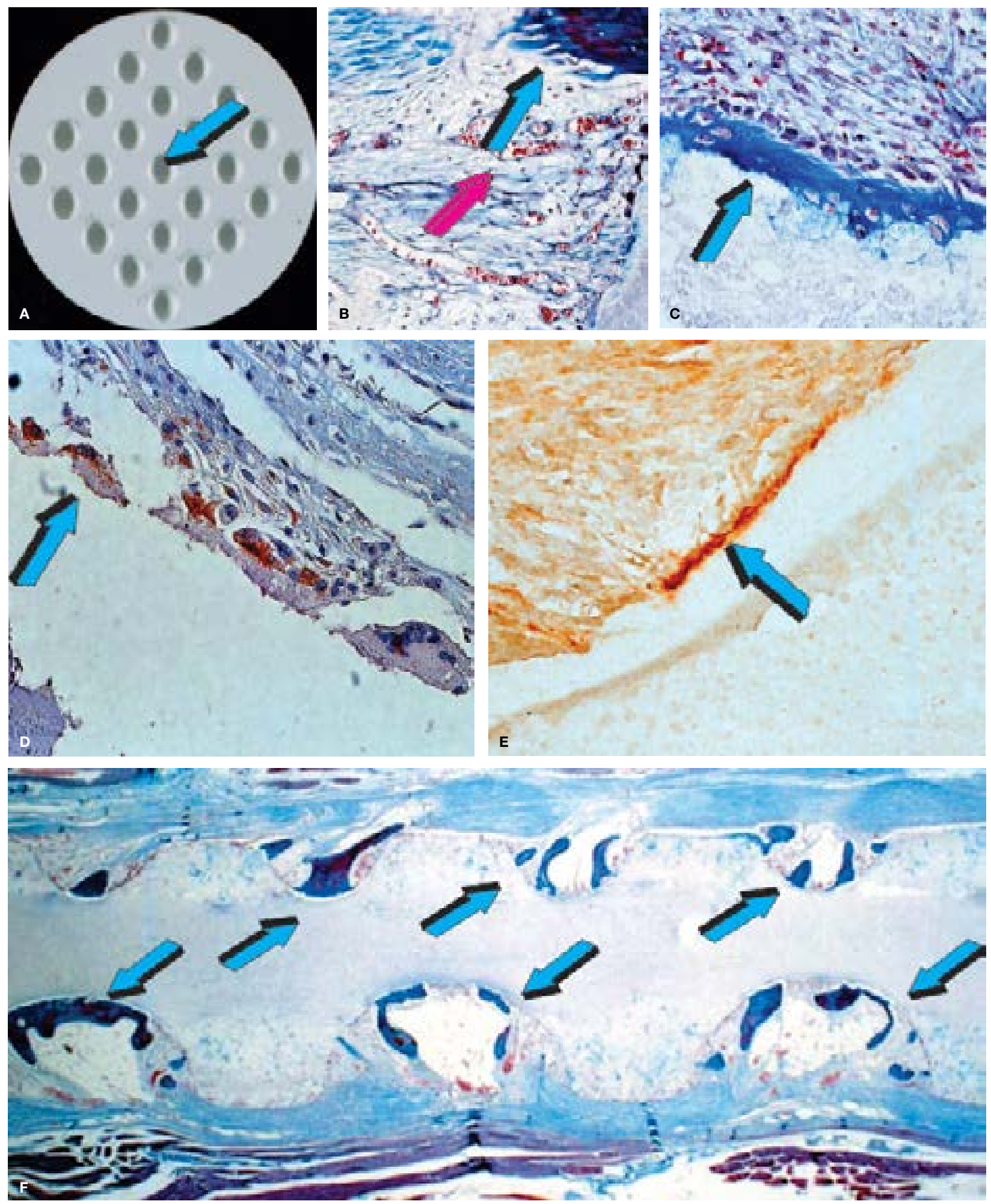

Figure 11. The "concavity motif" and the direct regulation of the spontaneous induction of bone formation by the geometry of the substratum: self-inductive geometric cues by sintered crystalline hydroxyapatites in disc configurations with concavities on both planar surfaces (A ligh blue arrow). ${ }^{43-53}$ Discs, implanted in heterotopic intramuscular sites of the Chacma baboon Papio ursinus, were processed for histological analyses on days 30 and 90.43-53 (B) Capillary sprouting and prominent angiogenesis almost touching the hydroxyapatite surface (B magenta arrow) with the induction of bone formation within the concavity of the substratum (B light blue arrow).

C. Spontaneous induction of bone formation at the base of a concavity (light blue arrow) of a sintered highly crystalline hydroxyapatite disc harvested on day 30 after heterotopic implantation. Newly formed bone by day 30 with contiguous plumped secreting osteoblasts. The newly formed bone matrix with embedded osteocytes tightly attach to the sintered

D. Immunolocalization of osteogenic protein-1 (OP-1) within the cytoplasm of mesenchymal cells differentiating into osteoblastic-like cells attached to the substratum (light blue arrow).

E. Synthesized OP-1 is expressed, secreted and embedded within the highly sintered crystalline substratum (light blue arrow).

F. Reproducible and constant induction of spontaneous bone formation within concavities of the substratum harvested on day 90 after heterotopic implantation. Bone, with the induction of haematopoietic none marrow, forms exclusively with the concavities of the substratum (light blue arrows), and without the exogenous application of the osteogenic soluble molecular signals of the TGF- $\beta$ supergene family.53-58 Decalcified sections cut at $6 \mu \mathrm{m}$ stained with Goldner's trichrome (B,C); original magnification $\times 125 ;(D, E) \times 95 ;(F) \times 17$. hydroxyapatite surface. 

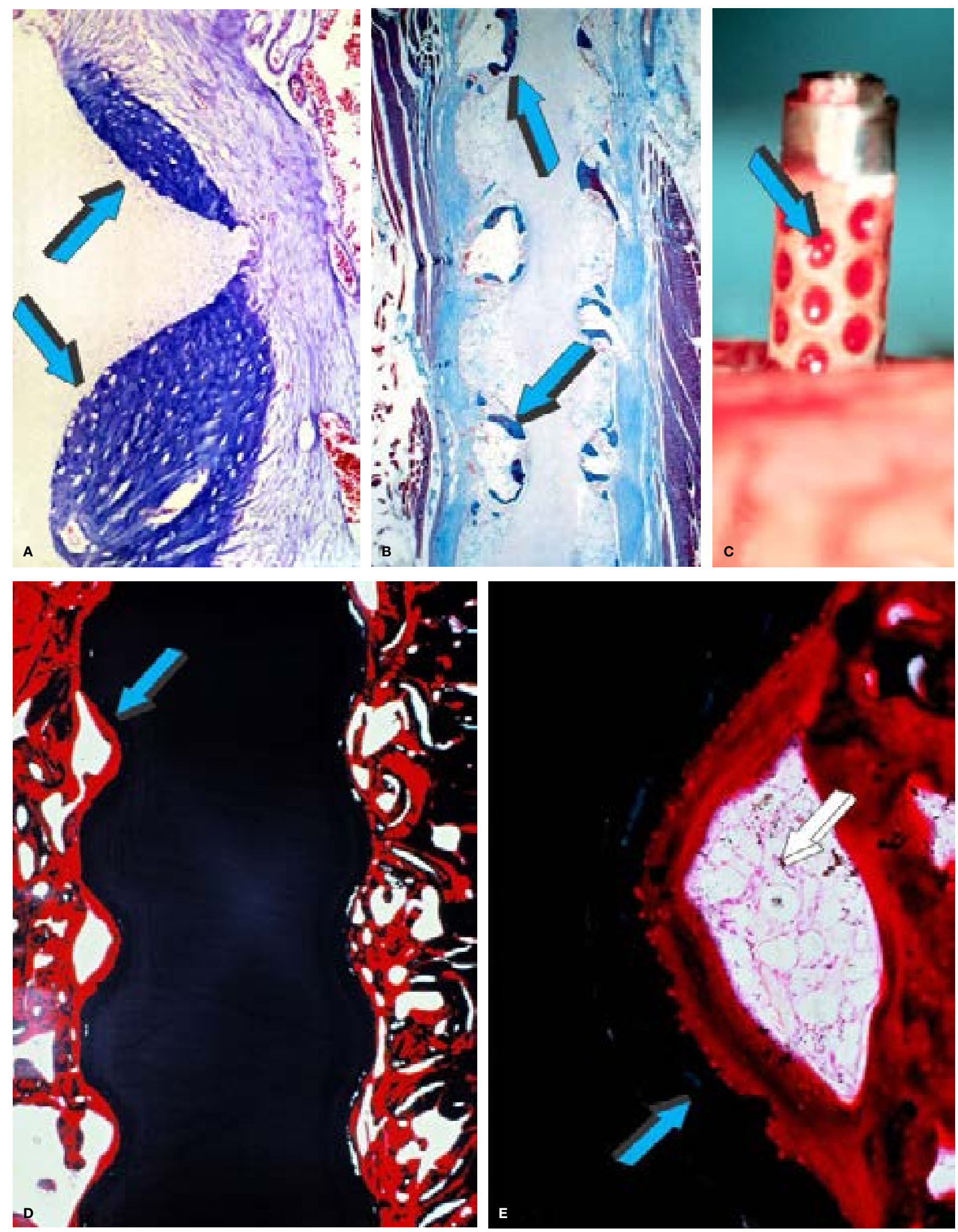

Figure 12. Biological and morphological rationale for translating the geometric induction of bone formation into solid titanium implants coated by highly crystalline sintered hydroxyapatite by plasma spraying methods. ${ }^{43-53}$ A. Spontaneous intrinsic induction of bone formation in concavities (light blue arrows) of a highly sintered hydroxyapatite construct on day 90 after heterotopic intramuscular implantation in Papio ursinus..$^{51-53}$

B. Sintered crystalline discs with concavities on both planar surfaces initiate the spontaneous induction of bone formation precisely in the concavities of the substratum only.

C. Translation of the geometric induction of bone formation in preclinical studies in Papio ursinus after manufacturing hydroxyapatite plasma sprayed titanium implants inserted in the ventral aspect of the tibia and

into mandibular edentulous ridges of Papio ursinus. ${ }^{51-53: 57,58}$ Absorption of plasma and plasma products within the concavities (light blue arrow) of the geometric construct.

E,F. Tissue induction and osteointegration of geometric titanium' constructs on day 90 after orthotopic implantation. Undecalcified tissue blocks were processed in ascending concentration of Technovit 7200 VLC (Heraeus Kulzer GmbH, Wehrheim, Germany) and embedded in the same resin. Undecalcified sections cut, ground and polished to 40-60 $\mu \mathrm{m}$ were stained with a modified Goldner's trichrome. ${ }^{.3,54}$

Sections were prepared using the EXAKT precision cutting and grinding system (EXAKT Apparatebau, Nordested, Hamburg, Germany). 57,58 

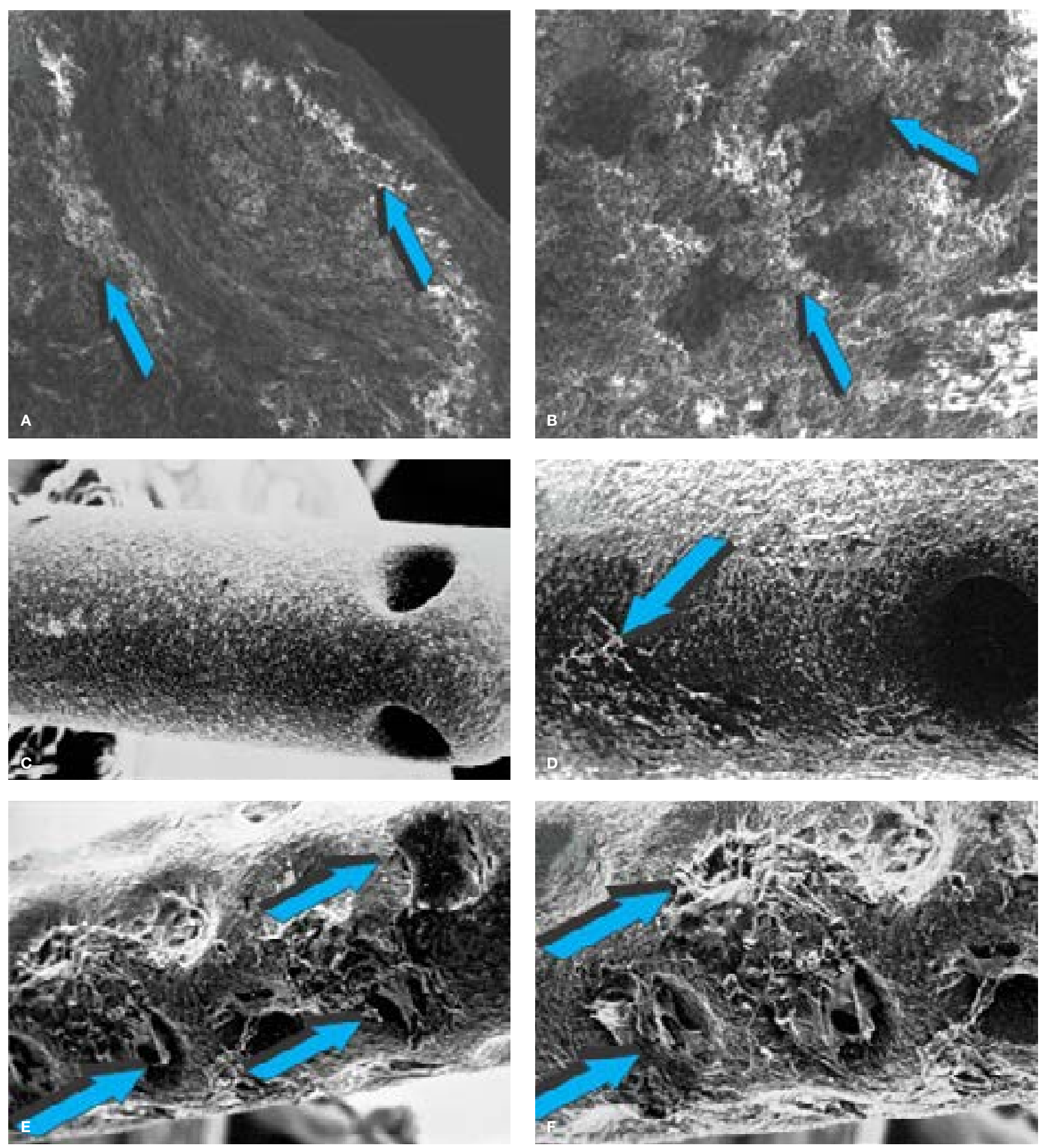

Figure 13. SEM analyses of hydroxyapatite-coated titanium implants. A,B. Image in A show the concavity of the substratum (light blue arrows) B. Coated titanium constructs show nanopatterned geometric modifications in the form of lacunae, pits and concavities of the plasma sprayed titanium constructs.

C,D,E,F. SEM analyses of titanium specimens harvested on day 5 after heterotopic implantation in the rectus abdominis muscle of the non-human primate Papio ursinus. ${ }^{68}$

C,D. Planar coated implant with minimal if any cellular activities along the surface (light blue arrow).

E,F. A very different image of biological cellular activities (light blue arrows) along the geometric substratum of the hydroxyapatite-coated titanium constructs. Myoblastic/pericytic cellular trafficking along the concavities of the heterotopically implanted constructs with resident cells attaching and stretching along the substratum nanotopography of the highly crystalline hydroxyapatite coating (light blue arrows). Harvested specimens on day 5 after rectus abdominis implantation were carbon-coated $(5 \mathrm{~nm}$ thick) and examined on a FEI Nova Nanolab SEM (FEI Company, Oregon, USA), at $30 \mathrm{kV}$. 
Therefore, the concavity is a prominent signal for cell attachment, orientation, palisading and differentiating events both in vitro and in vivo. ${ }^{43-53}$ Mouse-derived fibroblasts (NIH3T3) and pre-osteoblasts (MC 3T3-E1) were seeded onto coral-derived calcium carbonate/calcium phosphate constructs in disc configuration $(7 \mathrm{~mm}$ in diameter, $3 \mathrm{~mm}$ in height) simulating an in vitro bioreactor for cell attachment and differentiation. ${ }^{57,58}$

The concavities of the bioreactor effectively induced cellular orientation and alignment of MC 3T3-E1 cells along the geometric cues of the macroporous bioreactors (Fig. 15A).

EXACT precision cutting and grinding provided undecalcified sections at $170 \mu \mathrm{m}$, which showed the tight osteointegration of the hydroxyapatite-coated titanium with the newly formed remodelling bone on day 90 within the concavities of the substrata (Figs. 12D,E; 15C,D).

EXACT cut and ground undecalcified sections of specimen blocks harvested from the rectus abdominis muscle 31 months after implantation showed the induction of bone formation with mineralized newly formed bone surfacing the sintered hydroxyapatite coating, and covered by osteoid seams directly facing the rectus abdominis' microenvironment (Fig. 16).

This resulted in the first biotechnologically bioinspired biomimetic osteoinductive construct with the unique prerogative of being per se osteoinductive without the exogenous application of the osteogenic soluble molecular signals of the TGF- $\beta$ supergene family, and it was immediately available for translation in clinical contexts. ${ }^{53,57,58}$ We later mechanistically resolved the induction of bone formation within concavities of calcium phosphate-based macroporous constructs by invoking the critical role of osteoclastogenesis in releasing $\mathrm{Ca}^{++}$for the induction of angiogenesis and of the osteoblastic phenotype.

This is accompanied by an up-regulation of a specific subset of BMPs with an embedding of the secreted gene products within the concavities of the substratum, initiating the induction of bone formation as a secondary response. ${ }^{46}$

Geometric induction of tissue morphogenesis: substrata' stiffness and elasticity guide cell differentiation

The question that remains and should now drive biomaterial science, molecular medicine and tissue engineering alike, is how to construct biomimetic matrices that in their own right set into motion specific inductive phenomena without the exogenous application of recombinant human morphogens.

The goal is to construct intrinsically osteoinductive biomaterial surfaces, possibly defined as self-inductive surfaces, that per se, intrinsically, initiate tissue induction and morphogenesis. Discoveries in the last century showed that the geometry of the inductor, i.e. demineralized tooth dentine or different geometries of demineralized bone matrix particles, did have a profound influence on the induction cascade ${ }^{21-24}$ (Fig. 2).
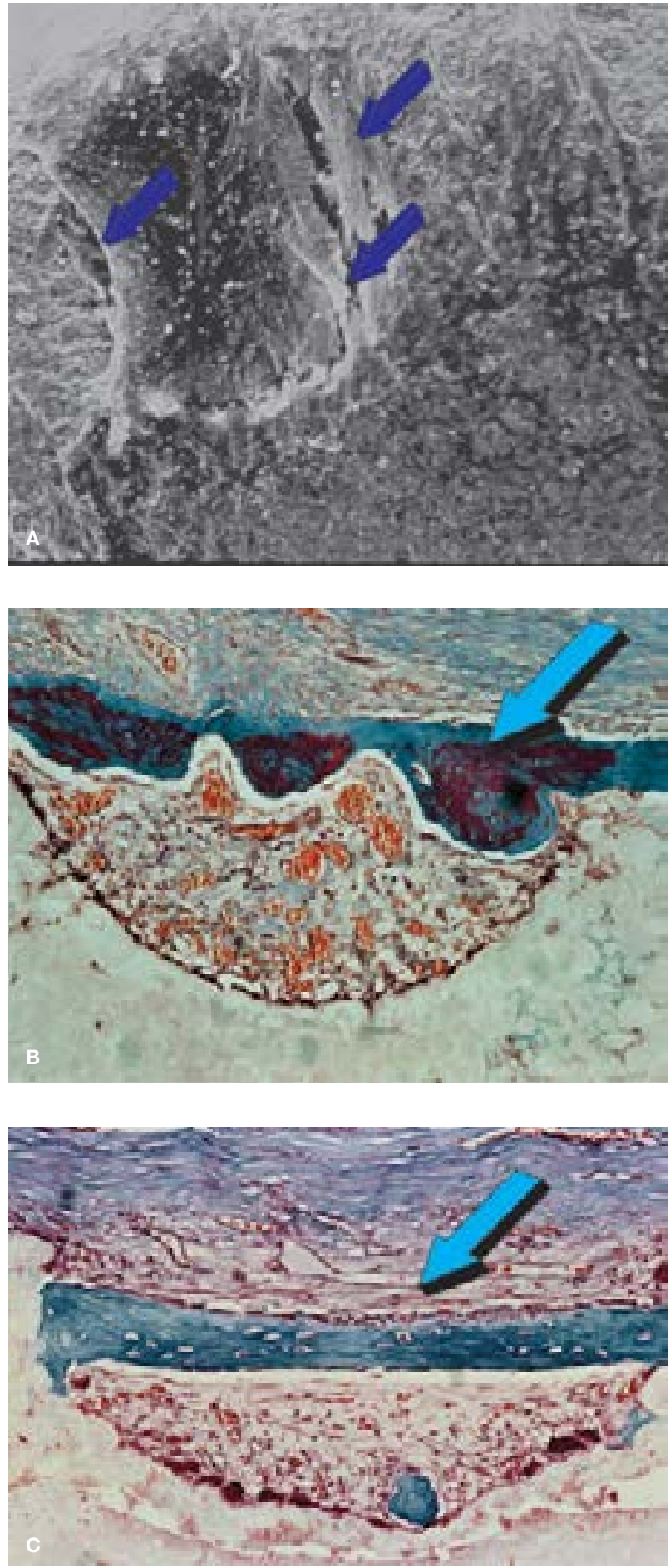

Figure 14. A. Collagenous condensations (dark blue arrows) stretching across a concavity of a hydroxyapatite-coated titanium implant 5 days after implantation in the rectus abdominis muscle of the non-human primate Papio ursinus. The scanning electron macroscopy (SEM) image depicts tractional patterning forces of fibroblastic/myofibroblastic-like cells secreting collagen fibres whilst moving from the edges of the concavities across the concavities of the hydroxyapatite-coated substratum. The SEM image (A) predates thus the spontaneous induction of bone formation across the concavity bioreactors on day 90 bridging the margins of the exposed concavities exposed to the rectus abdominis striated muscle (B,C).

B. The bridging bone (light blue arrow) separate the vascular microenvironment subjacent to the newly formed bone from the external rectus abdominis microenvironment (light blue arrow) with several macrophage/ poly-nucleated osteoclastic cells surfacing the hydroxyapatite interface. B,C. Transformation of collagenous condensation across concavities into bone matrix 90 days after heterotopic implantation in the rectus abdominis muscle of the non-human primate Papio ursinus.

(B,C) Decalcified sections cut at $6 \mu \mathrm{m}$ stained with toluidine blue in $30 \%$ ethanol. Original magnification $(B, C) \times 37$. 

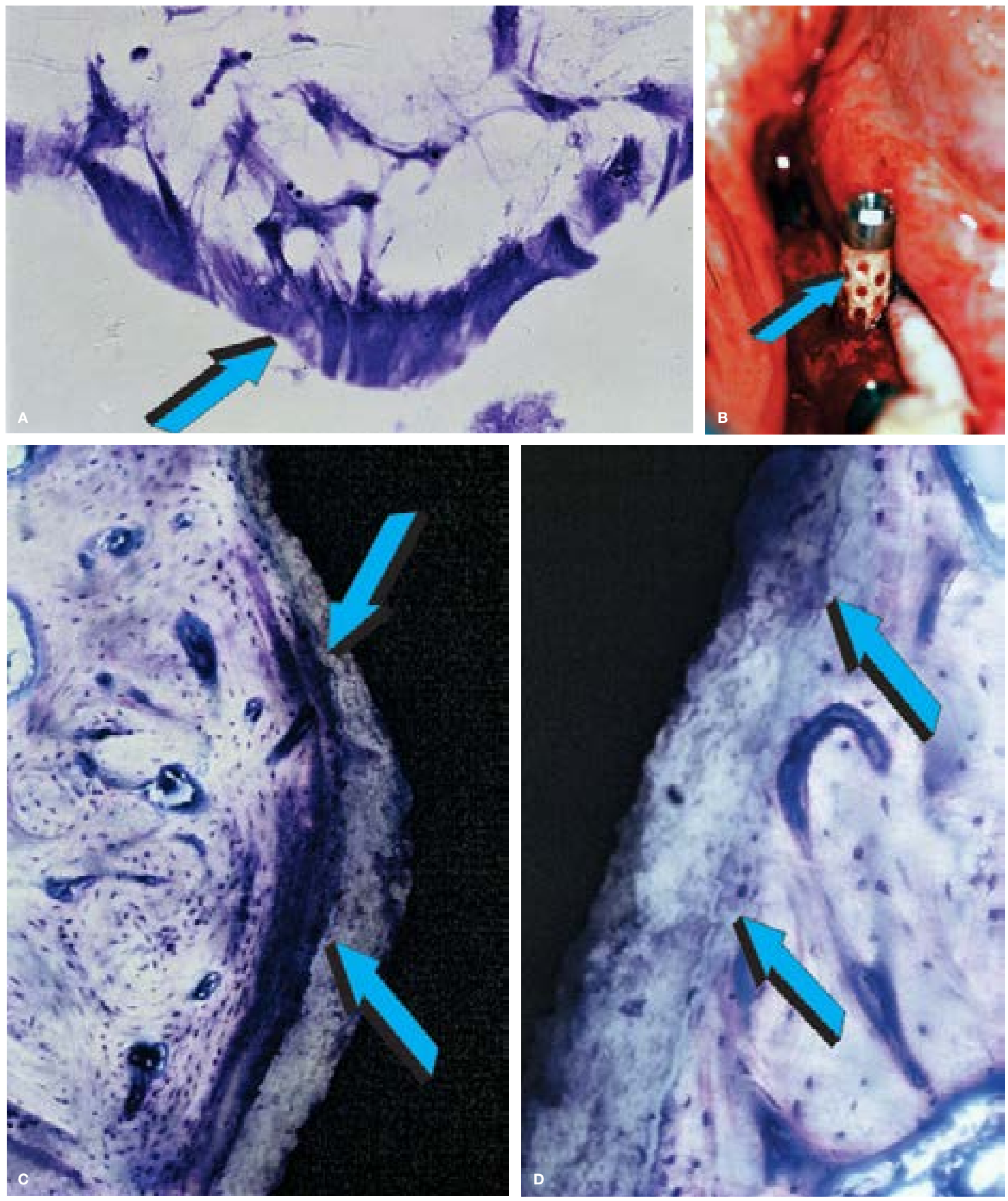

Figure 15. Further conceptualization of the pre-clinical translation of the geometric induction of bone formation into self-inductive hydroxyapatitecoated titanium implants.

A. Patterned attachment, alignment and orientation of MC 3T3-E1 cells grown in vitro onto geometric cues of coral-derived hydroxyapatite constructs: the effect of the geometric cue on in vitro cell alignment and patterning. ${ }^{57,58}$

B. Pre-clinical translation in edentulized mandibular ridges in Papio ursinus with selected uptake of plasma and plasma products by the concavity (ligh blue arrow).

C,D. High magnification of undecalcified osteointegrated sections along concavities of the hydroxyapatite-coated titanium constructs (light blue arrows). The digital images show the tight bond of the newly generated bone within concavities tightly osteointegrated with the plasma sprayed crystalline hydroxyapatite, perfectly matching the newly generated bone (light blue arrows). (C,D) undecalcified Exakt' sections, original magnification $(\mathrm{C}, \mathrm{D}) \times 175$. 
Half a century later a start has been made in the mechanistic assignment of the geometric influence on gene expression and cell differentition. A series of lucid and clear contributions have recently emerged highlighting that "stem cells feel the difference", 60 that "tissue cells feel and respond to the stiffness of their substrate", ${ }^{61}$ and that "matrix elasticity directs stem cell lineage specification". 62

We believe that the findings that "soft matrices that mimic brain are neurogenic" and that "comparativelyrigid matrices that mimic collagenous bone prove to be osteogenic"60 is the most significant contribution so far to the understanding of physical and geometric forces controlling the stem cell microenvironment and the induction of tissue morphogenesis.60.62

Selected genes are found to be up regulated including BMP-2 and BMP-7, RUNX2 and BGLAP. ${ }^{61-83}$

There are also focal adhesion (FA) structures controlling actin contractility and the mechano-transduction pathway by focal adhesion kinase (FAK) ultimately up
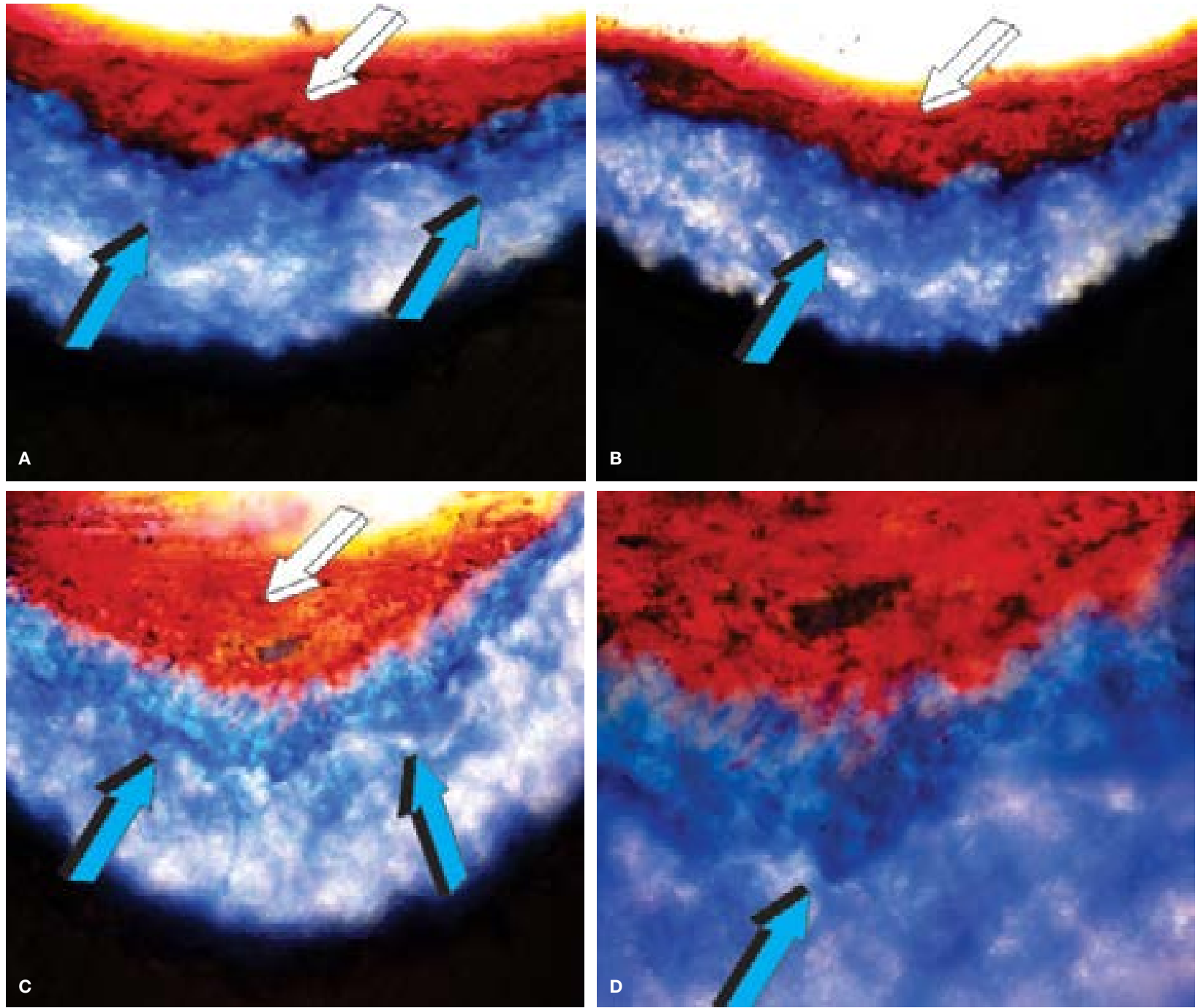

Figure 16. First generation titanium implants with geometric self-inductive configurations: Constructs were implanted in the rectus abdominis muscle of Papio ursinus ${ }^{57,58}$ and harvested 31 months after heterotopic implantation. A,B,C,D. Undecalcified sections representing the concavities prepared in the titanium constructs show the induction of bone formation (light blue regulating the transcriptor factor $R U N X 2$, controlling osteoblastic differentiation and matrix synthesis.

In his Cell paper62, Disher asks the final question: "how do stem cells feel or sense matrix elasticity and transduce that information into morphological changes and lineage specification?".

Actin structures are linked to FA structures and prothe elastic matrix. ${ }^{62}$ Disher further provides evidence that one of the cell's cytoskeletal motors, the non-muscle myosin (NMM) II isoform, is involved in sensing the matrix elasticity that guides lineage cell specification. ${ }^{62}$

Important research by Curran et al. ${ }^{70}$ has shown that controlled modifications of surface topographies guide mesenchymal cell differentiation in vitro by expressing and up-regulating collagen type I, osteocalcin, osteonectin, osteopontin and Cbfa1. Cbfa1 is a key regulator of osteoblasts differentiation in vivo but also of osteoblastic function. ${ }^{85}$ vide the pathway of force transmission from the cell to

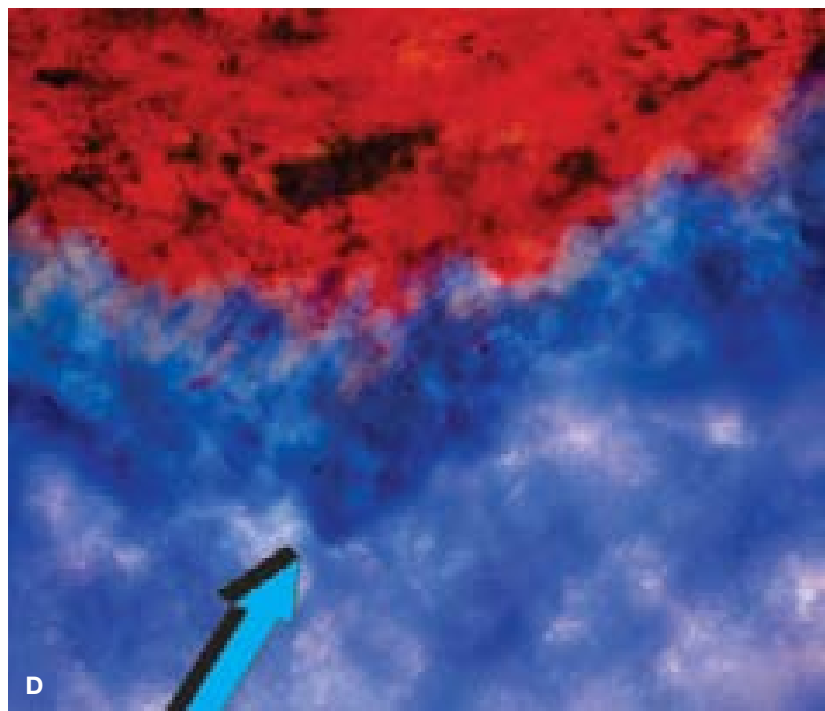

arrows) tightly attached to the hydroxyapatite plasma sprayed over the titanium geometric construct. Osteoid seams (white arrows) surface the newly formed mineralized bone. Undecalcified sections prepared by the Exakt diamond saw at $40-60 \mu \mathrm{m}$. Original magnification $(A, B, C) \times 175$; (D) $\times 225$. 
Submicron topographically patterned ridges and grooves modulate osteogenic differentiation in human mesenchymal stem cells by up-regulating RUNX2 and osteocalcin. ${ }^{63-65}$

Functionalization of the topographies of surfaces has been proposed by McNamara's group ${ }^{76,77}$ who report that in vitro cell responses to $15 \mathrm{~nm}$ high nanopillars resulted in larger focal adhesion, up-regulation of the osteogenic transcription factor RUNX2 and osteocalcin, contributing to the greater osteogenic capacity of the nanopatterned substrata. ${ }^{75,76}$

Similarly, nanotopographic cues control the fate and differentiation of adult stem cells when using scalable nanopatterns with defined densities of nanoposts ultimately "proposing engineering synthetic tissues with complex geometric organizations". 81

Geometrically modulated elastomeric substrata do mechanistically regulate cell function with an impact on cell morphology and stem cell differentiation. ${ }^{81-83}$ Recent reports have shown the effect of subcellular geometry in regulating stem cell differentiation. ${ }^{86}$ Micropillar geometrical arrays control cell differentiation and the osteogenic phenotype, altering the geometry of the cell nuclei, ${ }^{86}$ a new cue that regulates cell differentiation at the subcellular level. ${ }^{86}$

\section{PERSPECTIVES AND LIMITATIONS: BEYOND MORPHOGENS AND STEM CELLS}

The theme of geometry in the regulation of cell differentiation, cellular transformation and the induction of the osteogenic phenotype was set last century by the seminal discoveries of Reddi's group..$^{21-24}$

This critical contribution to the geometric influence on differentiation and transformation of fibroblasts is however still poorly understood, and even more poorly cited in the so many articles flourishing at IOSA, reporting the effect of geometry on the pathways of cell differentiation. These include, but are not limited to, the geometric control of capillary architecture 87 as well as geometric cues for directing stem cell differentiation. ${ }^{80}$ Indeed tissue geometry also deter mines the sites of branching morphogenesis in the mammary gland. ${ }^{88}$

The geometric control of capillary morphogenesis ${ }^{87}$ introduces yet again the Trueta ${ }^{54}$ "osteogenetic vessels" providing evidence that "angiogenesis is a prerequisite for osteogenesis." 54 Following those seminal studies of Trueta on the identification of osteogenetic vessels, recent reports highlight that signalling by endothelial Notch activity promotes endothelial cell proliferation, vessel growth in post- natal long bones and initiates both angiogenesis and osteogenesis in bone. ${ }^{89}$

In further studies, Kusumbe et al. ${ }^{90}$ uncovered structurally different capillary subsets with different morphological, molecular and functional properties. These molecularly distinct capillary subsets mediate growth of the bone vasculature, generate distinct molecular microenvironments, and maintain perivascular osteoprogenitors.
This coupling of angiogenesis to osteogenesis, ${ }^{90}$ provides further molecular evidence for the Trueta "osteogenetic vessels". ${ }^{54}$ Watari et al. ${ }^{79}$ showed that the combination of soluble molecular osteoinductive media together with topographical cues set by $400 \mathrm{~nm}$ pitch surface topography significantly enhanced the expression of osteogenic genes including RUNX2 and BGLAP. ${ }^{78}$ Vlacic-Zischke et al. ${ }^{80}$ and Ahn et al. ${ }^{81}$ further reported the spatial control of adult stem cell differentiation by nanotopographic cues. ${ }^{80,81}$

The latter study showed that the induction of osteogenesis markers by mesenchymal stem cells and/or pericytes is dependent on the geometric density of the nanoposts on the substratum, providing evidence that the nanotopography of the substratum controls stem cell differentiation and outcome. ${ }^{81}$

Modifying the geometries and nanotopographies of surfaces has been and still is a fascinating scenario of tissue and molecular biology. In vitro work, however, together with results in animal models, including nonhuman primate species, may well not adequately reproduce the results of the application of morphogens as conducted in Homo sapiens, where the capacity to regenerate has been severely dwarfed through evolution by either the discarding or acquiring of gene pathways inconsistent with tissue induction and regeneration.

What it is that makes the primate Homo sapiens heal with difficulties and uninspiringly when compared with animal models, including non-human primates?

What did Homo sapiens genetically lose or gain along the continuously unravelling of the marvellous molecular and biological adventure of human evolution?

Only a concerted genetic and molecular approach comparing animal phyla genomes will break the boundaries of super healing. Until that day is reached, tissue engineering and regenerative medicine in man will remain a dream.

\section{ACKNOWLEDGMENTS}

This contribution is dedicated to the fathers of the fascinating phenomenon of the "geometric induction of bone formation" with special thanks to Hari A Reddi for the introduction to the topic back in the eighties in Bethesda when he was Chief of the Bone Cell Biology Section at the NIH.

The presented work is supported in part by the University of the Witwatersrand, Johannesburg, the National Research Foundation, and by several ad hoc grants to the Bone Research Laboratory of the University.

Barbara van den Heever, Laura Roden neé Yates and Rooqayya Parak are gratefully acknowledged. A special thanks to the molecular team of the Bone Research Unit and the Laboratories of Molecular and Cellular Biology, School Clinical Medicine, Caroline Dickens, Therese Dix-Peek, and Nicolas Tagliatti. We thank William Richter and the late Michael Thomas, Council for Scientific and Industrial Research, Pretoria, for the preparation of the sintered calcium phosphate-based bioceramics for heterotopic implantation in Papio ursinus. 


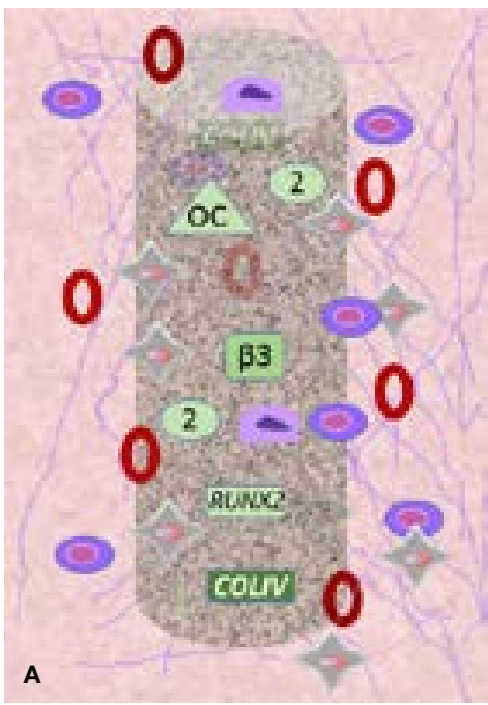

$15-30$

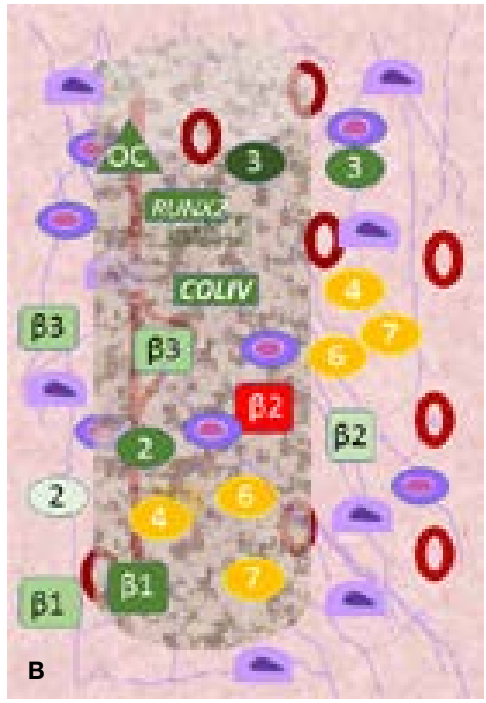

60

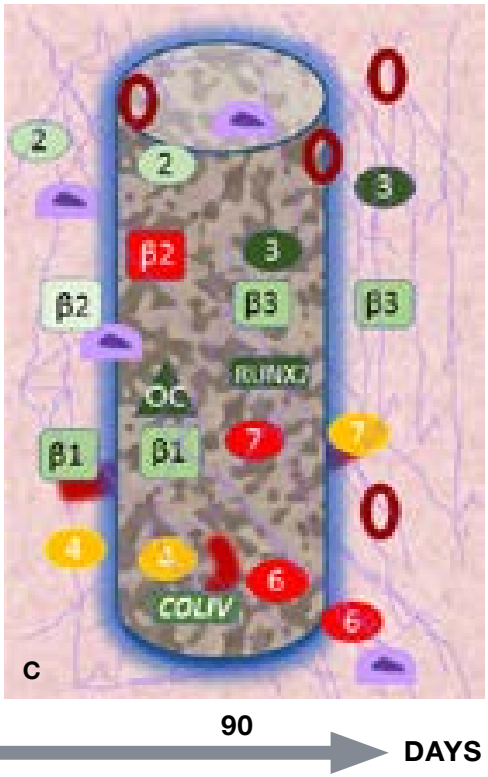

Muscle tissue

BMPs

TGF- $\beta$ s
Figure 17. Schematic representation of the spontaneous induction of bone formation by calcium carbonate coral - derived macroporous bioreactors. Macroporous bioreactors, implanted in the rectus abdominis muscles of the baboon Papio ursinus, were harvested on day $15(\mathrm{~A}), 30$ (B) and $90(\mathrm{C})$.

The interaction of the macroporous device with its unique geometry and the responding microenvironment of the rectus abdominis muscle initiate the bone induction signaling cascade. The relative expression profiles of key genes involved in the bone induction cascade are represented. Upregulated genes are indicated in green with the increase in intensity indicating increased expression levels. Genes colored in exhibited no change in expression relative to the control tissue. Down regulated genes are indicated in red.

On day 15 (A) peripheral spaces of the $7 \% \mathrm{HA} / \mathrm{CC}$ bioreactors are invaded by vascular connective tissue and parallels a pronounced upregulation of $\mathrm{Col} \mathrm{N}$ gene expression. Resident mesenchymal stem cells (MSCs) populations are stimulated to differentiate along the osteoblastic lineage as indicated by the upregulation of $\mathrm{OC}$ and transcription regulator of the bone forming expression programme.

\section{References}

1. Alkonti A. Patterns of bone induction by coral-derived vs. highly sintered crystalline hydroxyapatites. Master of Science in Dentistry (MSc Dent), University of the Witwatersrand, Johannesburg; 2017: 1-47.

2. Ripamonti U. Inductive bone matrix and porous hydroxyapatite composites in rodents and nonhuman primates. In: Yamamuro T, Wilson-Ench J, Hench LL, eds. Handbook of Bioactive Ceramics - Volume II: Calcium Phosphate and Hydroxylapatite Ceramics: CRC Press, Boca Raton, FL, 1990; 245-53.

3. Ripamonti $U$. The morphogenesis of bone in replicas of porous hydroxyapatite obtained from conversion of calcium carbonate exoskeletons of coral. J Bone Joint Surg. 1991; 73-A: 692-703.

4. Cell Editorial. Pulling it all together. Cell 2014; 157: 1.

5. Urist MR. Bone: Formation by autoinduction. Science 1965; 150: 893-9.

6. Reddi $\mathrm{AH}$, Hugging $\mathrm{CB}$. Biochemical sequences in the transformation of normal fibroblasts in adolescent rats. Proc Natl Acad Sci USA. 1972; 69: 1601-5.

7. Turing AM. The chemical basis of morphogenesis. Philos Trans R Soc B Biol Sci. 1952; 237: 37-72.

8. Wolpert I. Positional information and the spatial pattern of cellular differentiation. J Theor Biol. 1996; 25: 1-47.
On day 60 (B), newly formed bone has formed in the cavities of the bioreactors. The spaces are now surfaced with osteoblasts that face the highly vascularized matrix. The bone induction cascade is represented at the molecular level by strong upregulation of BMP2, BMP3, and TGF- $B$ expression and moderate TGF- $\beta$ 3 expression. The expression levels of BMP4, 6 and 7 remain unchanged relative to the muscle control tissue. By day 90 (C) bone levels in the device has increased significantly and the remodeled blocks of lamellar bone can be seen throughout the macroporous spaces (newly formed bone shown in blue with dark grey areas representing newly formed bone in the device). Prominent capillary sprouting is also present. The importance of the responding microenvironment is highlighted by the expression of members of the BMP and TGF- $\beta$ family of genes in the muscle tissue adjacent to the implanted device. The differential expression pattern of the BMP and TGF- $\beta$ genes over the time course show that the spontaneous induction of bone in the heterotopic sites of the Chacma baboon is the result of the temporal and spatial expression of several genes whose activity have been carefully orchestrated by the intrinsic properties of the implanted calcium carbonate coral-derived macroporous bioreactors.

9. Gurdon JB, Bourillot PY. Morphogen gradient interpretation. Nature 2001; 413: 797- 803.

10. De Robertis EM. Spemann's organizers and self-regulation in amphibian embryos. Nat Rev Mol Cell Biol. 2006; 7: 296-302.

11. Kenszberg M, Wolpert I. Specifying positional information in the embryo: looking beyond morphogens. Cell 2007; 130: 205-9.

12. Wartlick O, Kicheva A, González-Gaitán M. Morphogen gradient formation. 2015; 1: a001255 http://cshperspectives. cship.org/.

13. Spemann $H$, Mangold $H$. Induction of embryonic primordial by implantation of organizers from a different species. Roux's Arch Entw Mech. 1924; 100: 599-638.

14. Sampath TK, Muthukumaran N, Reddi AH. Isolation of osteogenin, an extracellular matrix-associated bone-inductive protein, by heparin affinity chromatography. Proc Natl Acad Sci USA. 1987; 84: 7109-13.

15. Wozney JM, Rosen V, Celeste AJ, Mitsock LM, Whitters MJ, Kriz RW, Hewick RM, Wang EA. Novel regulators of bone formation: molecular clones and activities. Science 1988; 242: 1528-34.

16. Ripamonti U, Ramoshebi LN, Patton J, Matsaba T, Teare J, Renton L. Soluble signals and insoluble substrata: Novel molecular cues instructing the induction of bone. In: Massaro EJ, Rogers JM, eds. Chapter 15, The Skeleton: Humana Press, 2004; 217-27. 
17. Reddi $\mathrm{AH}$. Morphogenesis and tissue engineering of cartilage and bone: Inductive signals, stem cells, and biomimetic biomaterials. Tissue Eng. 2000; 6: 351-9.

18. Ripamonti U. Soluble osteogenic molecular signals and the induction of bone formation. Biomaterials 2006; 27: 807-22.

19. Lander AD. Morpheus unbound: Reimagining the morphogen gradient. Cell. 2007; 128: 245-56.

20. U Ripamonti U, Crooks J, Khoali L, Roden L. The induction of bone formation by coral- derived calcium carbonate/hydroxyapatite constructs. Biomaterials. 2009; 20: 1428-39.

21. Reddi $\mathrm{AH}$, Huggins $\mathrm{CB}$. Influence of geometry of transplanted tooth and bone on transformation of fibroblasts. Proc Soc Exp Biol Med. 1973; 143: 634-7.

22. Reddi $\mathrm{AH}$. Bone matrix in the solid state: Geometric influence on differentiation of fibroblasts. Adv Biol Med Phys. 1974; 15: 1-18.

23. Luyten FP, Cunningham NS, Muthukumaran N, Hammonds RG, Nevins WB, Woods WI, Reddi AH. Purification and partial amino acid sequence of osteogenin, a protein initiating bone differentiation. J Biol Chem. 1989; 264: 13377-80.

24. Reddi $\mathrm{AH}$. Extracellular matrix and development. In: Piez $\mathrm{KA}$, Reddi $\mathrm{AH}$, eds. Extracellular matrix biochemistry. Elsevier New York, 1984; 375-412.

25. Zheng B, Cao B, Crisan M, Sun B, Li G, Logar A, Yap S, Pollett JB, Drowley L, Cassino T, Gharaibeh B, Desay BM Huard J, Peault B. Prospective identification of myogenic endothelial cells in human skeletal muscle. Nat Biotechnol. 2007; 25: 1025-34

26. Crisan M, Yap S, Casteilla L, Chen CW, Corselli M, Park TS, et al. A perivascular origin for mesenchymal stem cells in multiple human organs. Cell Stem Cell 2008; 3: 301-13.

27. Ripamonti U, Ferretti C, Heliotis M. Soluble and insoluble signals and the induction of bone formation: Molecular therapeutics recapitulating development. J Anatomy. 2006; 209: 447-68

28. Ripamonti U, Ma S, Reddi $A H$. The critical role of geometry of porous hydroxyapatite delivery system in induction of bone by osteogenin, a bone morphogenetic protein. Matrix 1992; 12: 202-12.

29. Ripamonti U. Biomimetism, biomimetic matrices and the induction of bone formation. J Cell Mol Med. 2009; 13: 2953-72.

30. Ripamonti U, Heliotis M, Ferretti C. Bone morphogenetic proteins and the induction of bone formation: from laboratory to patients. Oral Maxillofac Surg Clin North Am. 2007; 19 575-89.

31. Hulbert SF, Young FA, Mathews RS, Klavitter JJ, Talbert CD, Stelling $\mathrm{FH}$. Potential of ceramic materials as permanently implantable skeletal prosthesis. J Biomed Mat Res. 1970; 4 433-56.

32. Levander G. Tissue induction. Nature 1945; 155: 148-9.

33. Reddi AR. Bone morphogenesis and modeling: soluble signals sculpt osteosomes in the solid state. Cell 1997; 89: 159

34. Ripamonti U, Duneas N. Tissue engineering of bone by osteoinductive biomaterials. Mat Res Soc Bull. 1996; 21: 36-9.

35. Sampath TK, Reddi AH. Dissociative extraction and reconstitution of extracellular matrix components involved in local bone differentiation. Proc Natl Acad Sci USA. 1981; 78: 7599-603

36. Sampath TK, Reddi AH. Homology of bone-inductive proteins from human, monkey, bovine and rat extracellular matrix. Proc Natl Acad Sci USA. 1983; 80: 6591-5.

37. Reddi AH. Symbiosis of biotechnology and biomaterials: Applications in tissue engineering of bone and cartilage. J Cell Biochem. 1994; 56: 192-5.

38. Özkaynak E, Rueger DC, Drier EA, Corbett C, Ridge RJ, Sampath TK, Oppermann H. OP-1 cDNA encodes an osteogenic protein in the TGF-beta family. EMBO J 1990; 9 : 2085-93.
39. Celeste AJ, lannazzi JA, Taylor RC, Hewick RM, Rosen V, Wang EA, Wozney JM. Identification of transforming growth factor $\beta$ family members present in bone inductive protein purified from bovine bone. Proc Natl Acad Sci USA. 1990; 87: 9843-7.

40. Urist MR, Silverman BF, Büring K, Dubuc FL, Rosenberg JM. The bone induction principle. Clin Orthop Relat Res. 1967; 53: 243-83.

41. Ripamonti U, Van den Heever B, Van Wyk J. Expression of the osteogenic phenotype in porous hydroxyapatite implanted extra skeletally in baboons. Matrix 1993; 13: 509-17.

42. Ripamonti U. Osteoinduction in porous hydroxyapatite implanted in heterotopic sites of different animal models. Biomaterials 1996; 17: 31-5.

43. Ripamonti U, Crooks J, Kirkbride AN. Sintered porous hydroxyapatites with intrinsic osteoinductive activity: geometric induction of bone formation. S Afr J Sci. 1999; 95: 335-43.

44. Ripamonti U. Smart biomaterials with intrinsic osteoinductivity: Geometric control of bone differentiation. In Davies JE, ed. Bone Engineering, EM2 Corporation: Toronto, Canada, 2000; 215-22.

45. Ripamonti U. Osteogenic proteins of the TGF- $\beta$ superfamily. In Henry $\mathrm{HL}$ and Norman AW, eds. Encyclopedia of Hormones Austin Academic Press, 2003; 80-6.

46. Klar RM, Duarte R, Dix-Peek T, Dickens C, Ferretti C, Ripamonti $U$. Calcium ions and osteoclastogenesis initiate the induction of bone formation by coral-derived macroporous constructs. J Cell Mol Med. 2013; 17: 1444-57.

47. van Eeden SP, Ripamonti U. Bone differentiation in porous hydroxyapatites in baboons is regulated by the geometry of the substratum: implication for reconstructive craniofacial surgery. Plast Recontr Surg. 1994; 93: 959-66.

48. Ripamonti U. The concavity: The "shape of life" and the control of bone differentiation - Feature Paper - Science in Africa 2012. http://www.scienceinafrica.co.za/2012/Ripamonti bone.htm.

49. Ripamonti U, Roden L, Renton L, Klar R, Petit J-C The influence of geometry on bone: formation by autoinduction. - Feature Paper - Science in Africa 2012. http://www. scienceinafrica.co.za/2012/Ripamonti_bone.htm.

50. Ripamonti U. Soluble, insoluble and geometric signals sculpt the architecture of mineralized tissues. J Cell Mol Med. 2004; 8: 169-80.

51. Ripamonti U. Method for inducing extra-skeletal bone growth in primates and for screening implants therefore. US Patent Number: 5, 355, 898, October 18, 1994.

52. Ripamonti U, Kirkbride AN. Biomaterial and bone implant for bone repair and replacement. PCT/NL95/00181 PCT Pub. No. WO95/32008, Nov. 30. 1995.

53. Ripamonti U, Kirkbride AN. Biomaterial and bone implant for bone repair and replacement. US Patent Number: 6, 302, 913 B1, October 16, 2001.

54. Trueta J. The role of the vessels in osteogenesis. J Bone Joint Surg. 1963; 45B: 402-18

55. Manolagas SC, Jilka RL. Bone marrow, cytokines, and bone remodeling. Emerging insights into the pathophysiology of osteoporosis. N Eng J Med. 1995; 332: 305-11.

56. Parfitt AM, Mundy GR, Roodman GD, Hughes DE, Boyce BF. A new model for the regulation of bone resorption, with particular reference to the effects of bisphosphonates. J Bone Miner Res. 1996; 11: 150-9.

57. Ripamonti U, Roden LC, Renton LF. Osteoinductive hydroxyapatite-coated titanium implants. Biomaterials 2012; 33: 3813-23.

58. Ripamonti U, Renton L, Petit J-C. Bioinspired titanium implants: The Concavity - the shape of life. In: Ramalingam, M, Vallittu, M, Ripamonti, U, Li EJ eds. CRC Press Taylor \& Francis, Boca Raton USA; Tissue Engineering and Regenerative Medicine. A Nano Approach; 2013; 6: 105-23.

59. Ripamonti U, Dix-Peek T, Parak R, Milner B. Profiling bone morphogenetic proteins and transforming growth factor- $\beta \mathrm{s}$ by hTGF- $\beta_{3}$ pre-treated coral-derived macroporous bioreactors: The power of one. Biomaterials 2015; 49: 90-102. 
60. Buxboim A, Discher DE, Stem cells feel the difference. Nature Methods 2010; 7: 695-7.

61. Disher DE, Janmey P, Wang Y-L. Tissue cells feel and respond to the stiffness of their substrate. Science 2005; 310 : 1139-43.

62. Engler AJ, Sen S, Sweeney HL, Disher DE. Matrix elasticity directs stem cell lineage specification. Cell 2006; 126: 677-89.

63. Curtis A, Wilkinson C. Topographical control of cells. Biomaterials 1997; 18: 1573-83.

64. Clark P, Connolly P, Curtis ASG, Dow AT, Wilkinson CDW. Topographical control of cell behavior: I. simple step cues. Development 1987; 99: 439-48.

65. Clark P, Connolly P, Curtis ASG, Dow AT, Wilkinson CDW. Topographical control of cell behavior: II. multiple grooved substrata. Development 1990; 108: 635-44.

66. Bettinger CJ, Langer R, Borenstein JT. Engineering substrate topography at the micro- and nanoscale to control cell function. Angew Chem Int Ed. 2009; 48: 5406-15.

67. Kim D-H, Provenzano PP, Levchenko A. Matrix nanotopography as a regulator of cell function. J Cell Biol. 2012; 197: 351-60.

68. Lamers E, avn Horssen R, te Riet J, van Delft FCMJM, Luttge R, Walboomers XF, Jansen JA. The influence of nanoscale topographical cues on initial osteoblast morphology and migration. Eur Cells and Materials. 2010; 20: 329-43.

69. Chou Y-F, Huang W, Dunn JCY, Miller TA, Wu BM. The effect of biomimetic apatite structure on osteoblast viability, proliferation, and gene expression. Biomaterials 2005; 26 : 285-95.

70. Curran JM, Chen R, Hunt JA. The guidance of human mesenchymal stem cell differentiation in vitro by controlled modifications to the cell substrate. Biomaterials 2006; 27 : 4783-93.

71. Dalby MJ, Gadegaard N, Tare R, Andar A, Riehle MO, Herzyk P, Wilkinson CD, Oreffo ROC. The control of human mesenchymal cell differentiation using nanoscale symmetry and disorder. Nature Mat. 2007; 6: 997-1003.

72. Li X, van Blitterswijk CA, Feng $Q$, Cui F, Watari F. The effect of calcium phosphate microstructure on bone-related cells in vitro. Biomaterials 2008; 29: 3306-16.

73. Kulangara K, Leong KW. Substrate topography shapes cell function. Royal Soc Chem. 2009; 5: 4072-6.

74. You MH, Kwak MK, Kim D-H, Kim K, Levchenko A, Kim D-Y, Suh K-Y. Synergistically enhanced osteogenic differentiation of human mesenchymal stem cells by culture on nanostructured surfaces with induction media. Biomacromolecules 2010; 11: $1856-62$

75. Kilian KA, Bugarija B, Lahn BT, Mrksich M. Geometric cues for directing the differentiation of mesenchymal stem cells. Proc Natl Acad Sci USA. 2010; 107: 4872-7.

76. McNamara LE, Sjöström T, Burgess KEV, Kim JJW, Liu E, Gordonov S, Moghe V, Meek RMD, Oreffo ROC, Su B, Dalby MJ. Skeletal stem cell physiology on functionally distinct titania nanotopographies. Biomaterials 2011; 32: 7403-10.

77. McNamara LE, McMurray RJ, Biggs MJP, Kantawong F, Oreffo ROC. Nanotopographical control of stem cell differentiation. J Tissue Eng. 2010; 1-13 doi:10.4061/2010/120623.

78. Saha K, Mei Y, Reisterer CM, Pyzocha NK, Yang J, Muffat J, Davies MC, Alexander MR, Langer R, Anderson DG, Jaenish R. Surface-engineered substrates for improved human pluripotent stem cell culture under fully defined conditions. Proc Natl Acad Sci USA. 2011; 108: 18714-9.

79. Watari S, Hayashi K, Wood JA, Russel P, Nealey PF, Murphy CJ, Genetos DC. Modulation of osteogenic differentiation in hMSCs cells by submicron topographically-patterned ridges and grooves. Biomaterials 2012; 33: 128-36.

80. Vlacic-Zischke J, Hamlet SM, Friis T, Tonetti MS, Ivanovski S. The influence of surface microroughness and hydrophilicity of titanium on the up-regulation of TGF- $\beta$ /BMP signaling in osteoblasts. Biomaterials 2011; 32: 665-71.
81. Ahn EH, Kim Y, Kshitiz, An SS, Afzal J, Lee S, Kwak M, Suh K-Y, Kim D-H, Levchenko A. Spatial control of adult stem cell fate using nanotopographic cues. Biomaterials 2014; 35: 2401-10.

82. Logan N, Bozec L, Traynor A, Brett P. Mesenchymal stem cell response to topographically modified CoCrMo. J Biomed Mater Res Part A. 2015; 103A: 747-56

83. Fu J, Wang Y-K, Yang MT, Desai RA, Yu X, Liu Z, Chen CS. Mechanical regulation of cell function with geometrically modulated elastomeric substrates. Nat Methods. 2010; 7: 733-6.

84. Wilkinson A, Hewitt RN, McNamara LE, McCloy D, Dominic Meek RM, Dalby MJ. Biomimetic microtopography to enhance osteogenesis in vitro. Acta Biomater. 2011; 7: 2919-25.

85. Ducy P. Cbfa1: A molecular switch in osteoblast biology. Dev Dyn 2000; 219: 461-71.

86. Liu X, Liu R, Cao B, Ye K, Li S, Gu Y, Pan Z, Ding J. Subcellular cell geometry on micropillars regulates stem cell differentiation. Biomaterials 2016; 111: 27-39.

87. Sun J, Jamilpour N, Wang FY, Wong PK. Geometric control of capillary architecture via cell-matrix mechanical interactions. Biomaterials 2014; 35: 3273-80.

88. Nelson CM, van Duijn MM, Inman JL, Fletcher DA, Bissel MJ. Tissue geometry determines sites of mammary branching morphogenesis in organotypic cultures. Science 2006; 314: 298-300.

89. Ramasamy SK, Kusumbe AP, Wang L, Adams RH. Endothelial notch activity promotes angiogenesis and osteogenesis in bone. Nature 2014; 507: 376-80.

90. Kusumbe AP, Ramasamy SK, Adams RH. Coupling of angiogenesis and osteogenesis by a specific vessel subtype in bone. Nature 2014; 507: 323-8. 